\title{
Predominantly ligand guided non-covalently linked assemblies of inorganic complexes and guest inclusions
}

\author{
JUBARAJ B BARUAH*(i) \\ Department of Chemistry, Indian Institute of Technology Guwahati, Guwahati, Assam 781 039, India \\ E-mail: juba@iitg.ernet.in
}

MS received 15 December 2017; revised 29 March 2018; accepted 29 March 2018; published online 12 May 2018

\begin{abstract}
Various non-covalently linked inorganic self-assemblies formed by the supramolecular interacting sites located at the ligands are discussed. The impetus for this rapidly growing topic on the construction of robust assemblies is elucidated by select examples that are associated with interesting structures and properties. The review includes discussion on the stabilization of different assemblies of nucleobases in the non-covalent assemblies of inorganic complexes. The participation of the guest molecules in the formation of self-assemblies with hosts to make extra space or voids for intake of the guest, water-assisted assemblies, changes in the structures guided by cations, and aggregation-induced photoluminescence in the self-assemblies of metal complexes are presented. Fine-tuning of non-covalent self-assemblies of metal complexes by changing ligands or by other components, which modify the guest recognition abilities is elucidated. The discussions are based on selected examples of self-assemblies that use supramolecular features of peripheral part of ligands or ligand of a complex that helps one to identify templates for weak interactions and for molecular recognition.
\end{abstract}

Keywords. Inorganic complex; host-guest complex; molecular recognition; non-covalent interaction; selfassembly; supramolecular assembly.

\section{Introduction}

Stability as well as physical properties of non-covalently linked self-assemblies are collectively decided by weak interactions within them. ${ }^{1,2}$ Preliminary ideas on the primary interactions between the host and guest molecules help to choose the correct combination for preparation of host-guest complexes. For a complete understanding of self-assemblies of host-guest complexes, one has to consider different types of interactions existing between host and host, host and guest as well as guest and guest. ${ }^{3-7}$ On the other hand, a study on surface inclusion compounds with low activation energy barrier of $1.2-9 \mathrm{kcal} / \mathrm{mol}$ is useful to understand and control the directional molecular motions associated with those materials. ${ }^{8}$ Hosts and guests molecules may independently self-assemble in several ways such as the ones outlined in Figure 1. These selfassembling processes may be through, (a) formation of porous stable architecture to accommodate guests; ${ }^{9-12}$ (b) reorganization of originally non-porous selfassemblies of host molecules to hold guest

\footnotetext{
*For correspondence
}

molecules; ${ }^{13,14}$ (c) formation of self-assembly to provide hydrophobic or hydrophilic pockets of host molecules to accommodate guest molecules/ions as found in clathrates and water/ion clusters; ${ }^{15-22}$ (d) self-assembling between host and guest molecules to provide extra space for guests; ${ }^{23,24}$ (e) partial modification of selfassemblies of a host-guest complex to accommodate more/new guest molecules; ${ }^{25}$ (f) forming dendrimerlike assemblies to include guest molecules. ${ }^{26,27}$ These organized self-assembling processes are commonly used to achieve effective guest binding in non-covalently linked assemblies. The directional properties, stability, physical properties of these assemblies are essentially guided by overall impact of weak repulsive as well as attractive interactions among the components of each self-assembly. Besides conventional host-guest complexes, there are non-covalently linked assemblies containing voids where another chemical species gets encapsulated. These are called inclusion compounds where such voids or channels are occupied by guests. ${ }^{28,29}$ Self-assemblies of certain compounds have intrinsic voids ${ }^{30}$ and rest are self-assembled supramolecular assemblies originating from non-porous self-assemblies executing the performance similar to 


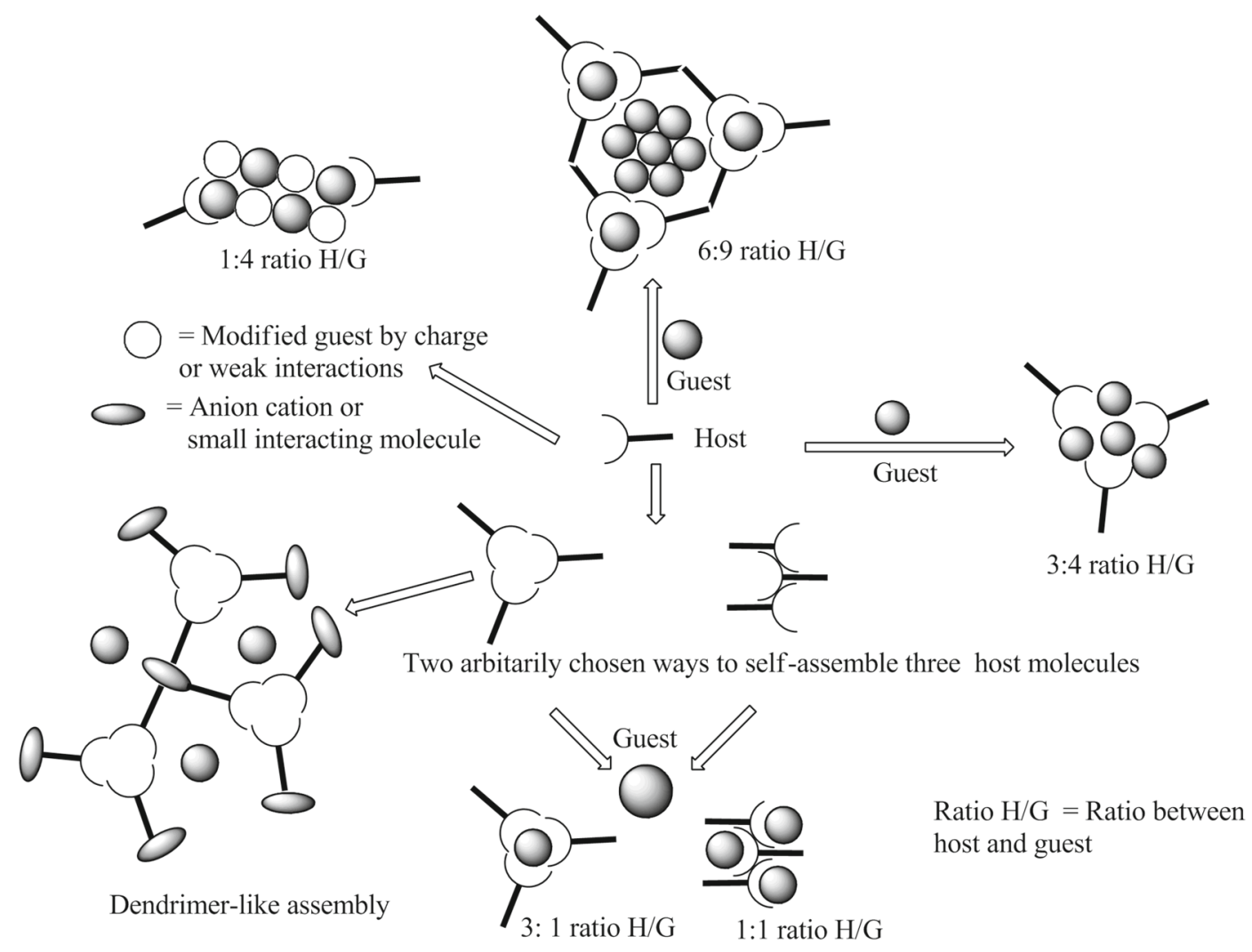

Figure 1. Schemes to modulate amounts of guest molecules in host-guest complexes.

porous structures by accommodating guests. ${ }^{31}$ In general, porous architectures with anions, cations and neutral molecules are less stable. Porous self-assemblies, often known as desolvates, are formed by loss of solvent of crystallization or guest molecules.

Host-guest chemistry through non-covalent interactions has grown rapidly over the years ${ }^{32-39}$ but systematic reports on non-covalently linked small inorganic complexes are relatively few. ${ }^{40-45}$ Coordination complexes having hydrogen bond donors or acceptors at peripheral sites are useful to design network structures. ${ }^{46,47}$ The $\pi$-stacking effect is realized as a major factor contributing to stability and physico-chemical properties of many self-assemblies. ${ }^{48-53}$ There are more hurdles to understand self-assemblies of inorganic complexes as metal ions bring versatility and complications through directional coordination, oxidation states, etc. The metal complexes with ligands are generally prepared in solution and solvent gets incorporated to ligand or crystallizes as a solvent of crystallization. Hence, the ability of an inorganic complex to accommodate solvent molecules of crystallization in lattice influences the architecture of self-assemblies. ${ }^{54-58}$ Increase in uptake of guest molecules in a self-assembly of the host is important to develop storage and delivery systems and in energy conversions. This aspect is routinely studied by changing the porosity of metal-organic frameworks. ${ }^{59}$ Inorganic chemists routinely use coordination polymers and metal-organic frameworks. But the self-assembling of coordination complexes through the peripheral effects of ligand to provide directional properties and different selfassemblies depicted in the Figure 1 warrant preparation of new supramolecular assemblies for advanced material properties. There are also definite concerns to evaluate properties of self-assembled inorganic complexes at the molecular level; such as, epitaxial growth of crystals in a controlled manner, self-assembled materials for future use as core-shell crystalline materials, and for neat bottom-up crystallization processes. ${ }^{60}$ The subject of self-assemblies of host-guest complexes is very large, hence certain intrinsic characteristic features which primarily control weak interactions are essential for the logical design of a selfassembly. Among such intrinsic features, $\mathrm{C}-\mathrm{H} \cdots \pi$ interactions ${ }^{61,62}$ and $\pi-\pi$ interactions ${ }^{63,64}$ contribute significantly to the respective packing patterns. Hierarchies of energies of different $\pi$-interactions ${ }^{65,66}$ are in general lower than strong or medium hydrogen bonds; yet, directional nature of these interaction makes indispensable contribution. Each self-assembling processes depicted in Figure 1 may have such contributions which 

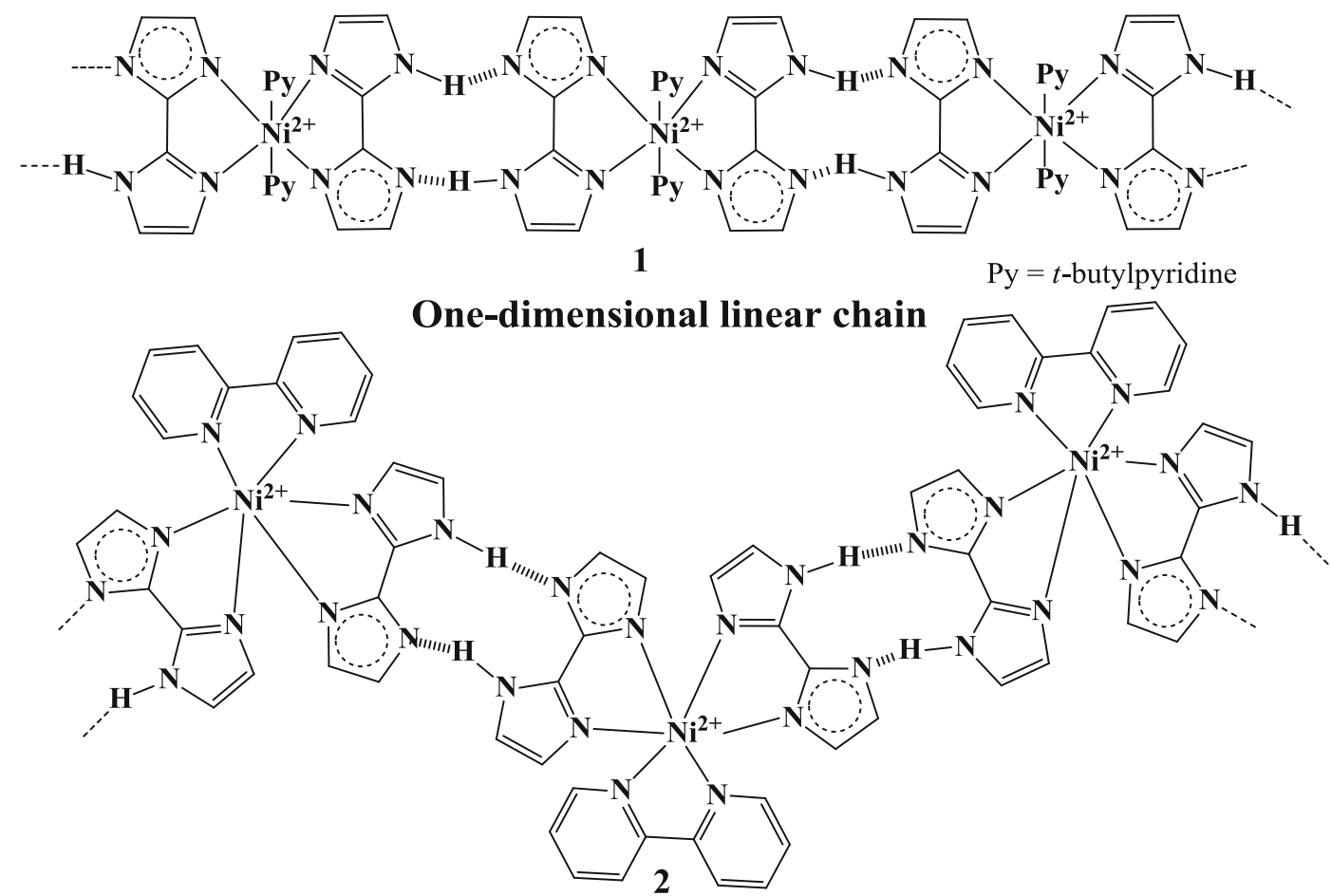

\section{One-dimensional zig-zag ribbon}

Figure 2. One-dimensional self-assemblies of nickel(II) 2,2'-biimidazolate complexes with different ancillary ligands.

necessitate one to understand their roles in conferring special features to physical and chemical properties of self-assemblies and host-guest systems. The implications of weak interactions in host-guest assemblies in chosen examples of mono- to tetra-nuclear inorganic complexes are discussed here. This article deals with a discussion on the non-covalently linked inorganic selfassemblies guided by the supramolecular features of the peripheral part of a ligand acting as a supramolecular template for host-guest inorganic complexes.

\section{Non-covalently linked self-assemblies of inorganic complexes}

Metal coordination and hydrogen bonds are routine parameters that influence self-organization of inorganic molecular crystals. Information on these two aspects as well as information on the lower hierarchical weak interactions helps to explain properties of such assemblies. As in the case of hydrogen-bonded organic self-assemblies, the conventional supramolecular self-assemblies of inorganic complexes are also formed by hydrogen bonds among the complexes. In self-assemblies of inorganic complexes, metal-metal interactions or $\pi$-metal interactions often come across as influencing factors in packing patterns. Self-assemblies of 2,2'biimidazolate metal complexes possess extensive hydrogen bonds to generate different types of superstructures depending on the status of the central metal ion, nature of counter ions, and ancillary ligands. ${ }^{67}$ Due to the directional nature of hydrogen bonds, the hydrogen bonded selfassemblies of 4,4'-biimidazolate metal complexes ${ }^{68}$ widely differ from the $2,2^{\prime}$-biimidazolate complexes. One-dimen sional linear chains, zigzag ribbons, helical structures and 2-dimensional honey-comb sheets were found in various nickel(II) tris-2,2'-biimidzolate complexes upon variations of the hydrogen bond schemes by changing organo-ammonium cations. ${ }^{67}$ The structures of a series of nickel(II) 2,2'biimidazolate complexes were also modulated by changing the orientations of 2,2'-biimidazolate ligands in the coordination sphere. For example, one-dimensional hydrogen bonded self-assembly 1 was formed when two tertiarybutylpyridine ligands occupied the trans-coordination sites of a distorted octahedral geometry of the complex (Figure 2a). A zigzag hydrogen bonded one-dimensional self-assembly 2 was formed when a 2,2'-bipyridine ancillary ligand was used to satisfy the two coordination sites of nickel-2,2' biimidazolate complex. Due to bidentate nature with a rigid geometry of the ligands, the 2,2'-bipyridine ligands occupy the cis-positions resulting in changes in the orientations of the 2,2'-biimidazolate ligands (Figure $2 \mathrm{~b}$ ) providing a one dimensional zigzag structure.

Metal complexes possessing suitably designed supramolecular features provide self-assemblies with interesting properties. For example, nicotinate anions held to 


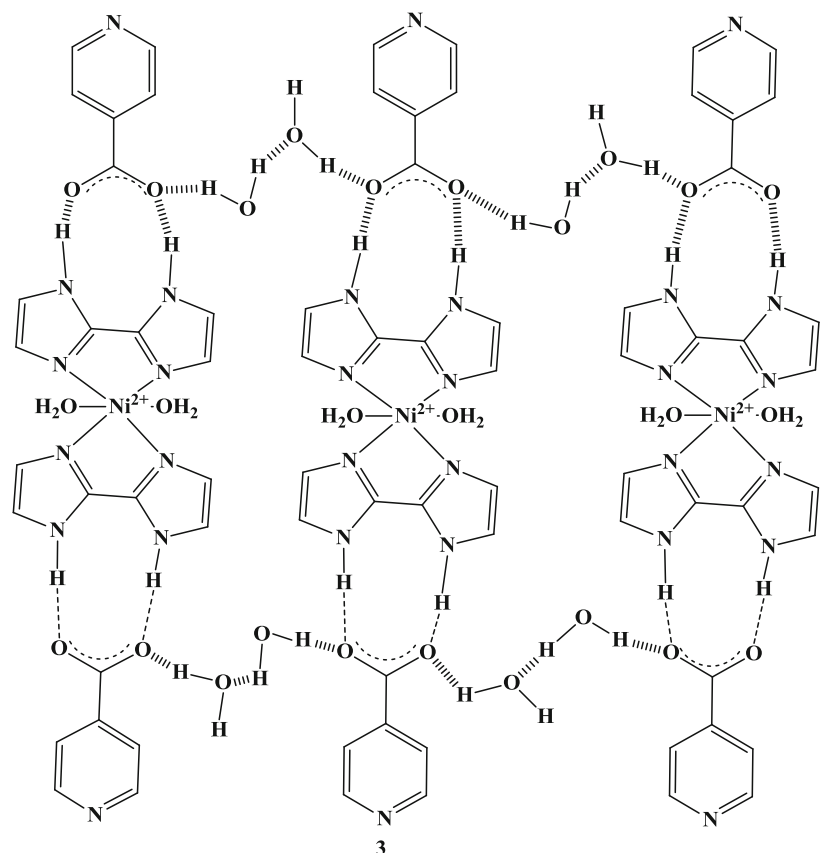

Figure 3. A water-assisted sheet-like hydrogen bonded self-assembly of bis-(2,2'-biimidazole)nickel(II) nicotinate dihydrate.

2,2'-biimidazole nickel(II) or cobalt(II) cationic complex anchor water molecules in crystal lattice (Figure 3 ). The carboxylate anions of the complex form hydrogen bonds with $2,2^{\prime}$-biimidazolate ligands. The water molecules present in the lattice knit the carboxylates to provide a sheet-like structure 3. ${ }^{69}$ Such water-assisted hydrogen-bonded assemblies undergo easy dehydration. In particular, the dehydration of such a silver complex under mild conditions was reversible; this was due to retaining the original backbone in the desolvate ensuring the reversible rehydration.

2,2'-Biimidazole containing metal complexes are versatile building blocks to construct a variety of architectures for inclusion complexes. ${ }^{70} \mathrm{~A}$ striking feature of $2,2^{\prime}$-biimidazole silver complexes is the ability to form anion dependent self-assemblies differing in packing patterns. For example, silver complexes of different nuclearities are formed upon change of the anions of silver-2,2'-biimidazole complexes. Such differences originating from the number of silver atoms linked together influence the overall architecture of individual self-assembly by varying the number of hydrogen bonding sites per molecule. ${ }^{71}$ Self-assembly of cobalt(III) mixed ligand complex derived from1,10-phenanthroline (phen) and 2,2'-biimidazole $\left(\mathrm{H}_{2}\right.$ biim $)$ with a composition $\left[\mathrm{Co}(\text { phen })_{2}\right.$ $\left(\mathrm{H}_{2}\right.$ biim $]\left(\mathrm{ClO}_{4}\right)_{3} \cdot 0.5\left(\mathrm{H}_{7} \mathrm{O}_{3}\right)\left(\mathrm{ClO}_{4}\right)$ utilizes the $\mathrm{N}-\mathrm{H}$ bonds of the 2,2'-biimidazole to bind with calf-thymus deoxyribonucleic acid (DNA). The complex gets anchored to DNA groove and it has binding constant $1.26 \times 10^{4} \mathrm{M}^{-1}$. Due to such binding with DNA, cleavage of the DNA under photochemical conditions gets facilitated. ${ }^{72}$

Cyanide is a highly polar ligand. When coordinated to a metal ion it acts as a good hydrogen bond acceptor. Accordingly, complex metal-cyanide ions participate in hydrogen

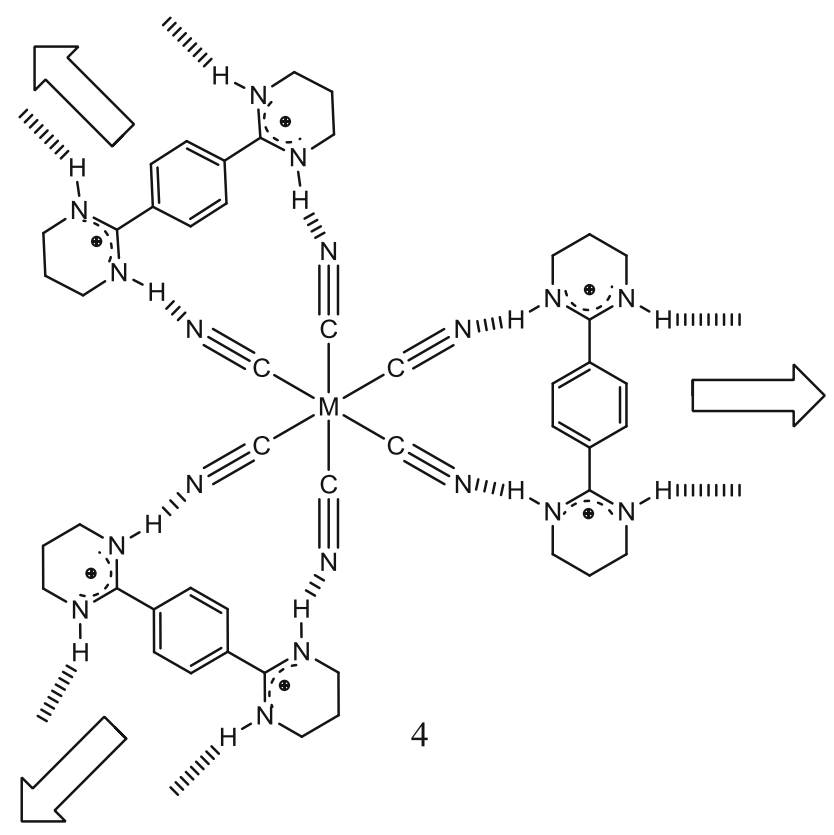

Figure 4. Self-assembling of hexacyanometallate with organocations.

bonding with organo-ammonium cations or solvents. For example, complex anions $\left[\mathrm{M}(\mathrm{CN})_{4}\right]^{2-}$ or $\left[\mathrm{M}(\mathrm{CN})_{6}\right]^{\mathrm{n}-}(\mathrm{M}=$ metal ion) possessing bis-amidinium cations form different hydrogen bonded molecular networks. One such assembly 4 is shown in Figure 4. Architectures of those assemblies depend on coordination geometry and coordination numbers of central metal ion. Number and location of hydrogen bonding sites on the cation dictate the directionality of such assemblies. $^{73}$

Cations in many complexes are derived by protonation in multiple nitrogen containing compounds. Such cations with favourable geometry act as hydrogen bond bridges form molecular networks. 4,4'-Bipyridinium and 4,4' -bipiperidinium ions are generally used to form molecular networks with $\left[\mathrm{MCl}_{4}\right]^{2-}(\mathrm{M}=\mathrm{Pd}, \mathrm{Pt}, \mathrm{Mn}, \mathrm{Cd}) .{ }^{74-78}$ Hybrid organicorganometallic as well as inorganic-organometallic noncovalently linked assemblies of such complexes with chargeassisted hydrogen bonds result in self-assemblies with different topologies. Many such assemblies are associated with interesting redox properties. ${ }^{79}$ Anion guided porous self-assemblies of silver bis-pyrazole complexes are well known. ${ }^{80}$

Urea-based metal complexes are well-known to provide hydrogen bonded self-assemblies. For example, $N, N^{\prime}$ dimethylurea-cobalt complexes form one or two-dimensional hydrogen-bonded self-assemblies. ${ }^{81}$ Similarly, multifunctional ligands with hydrogen bonding sites such as metal complexes of lactic acid also form interesting self-assemblies. For example, self-assemblies of the zinc lactate complex of cation $[\mathrm{Zn}($ metlc $)($ Hmetlc $)($ phen $)]$ and anion $\left[\mathrm{Zn}(\right.$ Hmetlc $\left.)(\text { phen })_{2}\right]$ $[$ Hmetlc $=$ methyl lactate mono-anion and metlc $=$ methyl lactate di-anion] form three-dimensional hydrogen-bonded 


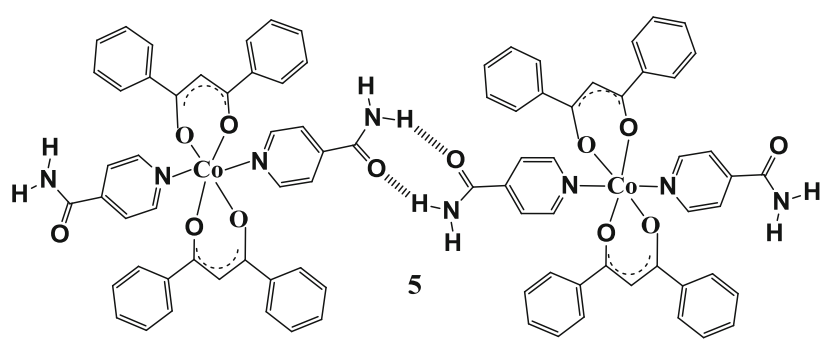

Figure 5. A wheel and axle type self-assembled host.

open framework; where water molecules get encapsulated. ${ }^{82}$ Honeycomb-like porous network is formed by self-assembling of tris(bipyridyl-glycoluril)cobalt(III) chloride. ${ }^{83}$ Shimizu and co-workers have reported the utility of simple yet interesting $\left[\mathrm{Co}\left(\mathrm{NH}_{3}\right)_{6}\right]^{3+}$ organosulfonates to form self-assembled structures with robust architecture wherein the triangular faces of the hexammine cobalt(III) complex provides sites for charge-assisted hydrogen-bonds. ${ }^{84}$

From these selective examples, it is clear that interplay of weak interactions in coordination behaviour of metal ions are the prime factors in building non-covalent self-assemblies of inorganic complexes. Various possibilities to build multinuclear complexes, to introduce new the supramolecular sites with the aid of ligands, to use of mixed ligand complexes, utilisations of the cationic or anionic part of complexes to generate new self-assemblies are open-ended issues. Furthermore, conformational flexibility, the chirality of metal complexes or ligands are additional avenues for non-covalent assemblies for advanced materials.

\subsection{Assemblies of chelated and macrocyclic ligand complexes}

Metal chelates use the hydrogen bond donor/acceptor sites on the ligand or stacking interactions to self-assemble. Either of these interactions influences packing pattern and affect their physical properties. Self-assemblies formed by such complexes are guided by solvents, reaction conditions and the supramolecular features on the peripheral part of the ligands. The peripheral part effects $\pi$-stacks or stacks for tight packing which influence the physical and chemical properties of the complexes.

Due to the effectiveness of weak interactions in the solid state the mechanochemical synthese are highly specific to generate interesting complexes. For example, chelate such as cobalt(II) dibenzoylmethanate dihydrate easily transforms to templates suitable for inclusion of guest molecules. Hexacoordinated cobalt(II) dibenzoylmethanate having nicotinimide ligands at two axial positions has a wheel and axle type structure. This structure helps the complex to serve as a template (Figure 5) to recognise different aromatic guest molecules. ${ }^{85}$ Planar aromatic guest molecules are easily accommodated over the spaces over the self-assembled amide units.

A product formed through a solid phase synthesis may differ from synthesis through solution phase due to
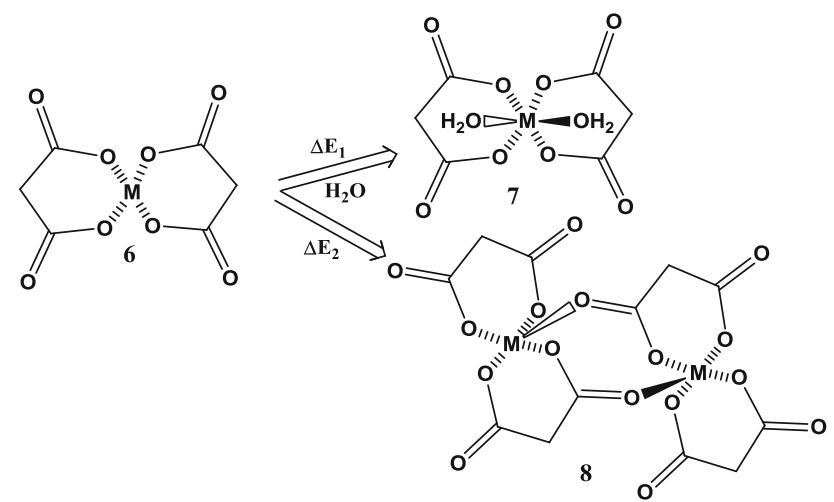

Figure 6. Hydration vs. dimerization of mononuclear bismalonate complex.

supramolecular interactions operational in the solid state more than in solution. For example, by variation of the reaction conditions, one may obtain a mononuclear or an aqua-bridged dinuclear cobalt 2-nitrobenzoate complex. Similarly, differences in products are observed upon manipulation of crystallization procedures/conditions. For example, crystallization from different solvents yield crystals of different polymorphs of aqua-bridged dinuclear cobalt 2-nitrobenzoate due to the different orientations of the nitrogroups. ${ }^{86}$

There exist large numbers of self-assemblies of homometallic or heterometallic malonate complexes. ${ }^{87-89}$ Copper(II) malonate complexes with mononuclear and dinuclear blocks shown in Figure 6 are reported in the literature. ${ }^{90}$ Cationic counterparts of those complexes control the thermal stability in the solid state. The preparation of a particular four coordinated square planar complexes is difficult as complication arises from hydration of the square planar complexes or from the propensity of square planar complexes to adopt square-pyramidal structures by dimerization as illustrated in Figure 6.

The energetic of bis-malonate metal complexes to get hydrated or to form dinuclear unit depends on the central metal ions. An energy calculation has shown that there is a $2.8 \mathrm{kcal} / \mathrm{mol}$ gain in energy to form dinuclear complex over hydrated copper(II) malonate complex; whereas such a gain in energy for the same process for cobalt(II) malonate complex is $3.5 \mathrm{kcal} / \mathrm{mol}$; and it is $1.2 \mathrm{kcal} / \mathrm{mol}$ for nickel(II) malonate complex. In this regard, magnesium malonate is an exceptional case; in this case, the hydration energy and the energy required to form dinuclear complex from the corresponding mononuclear magnesium malonate complex are comparable. Thus, a synthetic procedure has to accommodate these minute differences affecting stabilities. Energetically, these effects are very small; hence they are generally competing with solute-solvent interactions and the energy supplied by the external or internal source while performing such reactions. Hence, the reaction conditions make an impact on the formation of a desired self-assembly.

Aluminium and gallium complexes having composition $\left[\mathrm{M}(d p p)_{3}\right]$ where $\mathrm{M}=\mathrm{Al}$ or $\mathrm{Ga}$ and $H d p p=1,3-\operatorname{di}(4-$ pyridyl)-1,3-propanedione (Figure 7) are used as building 


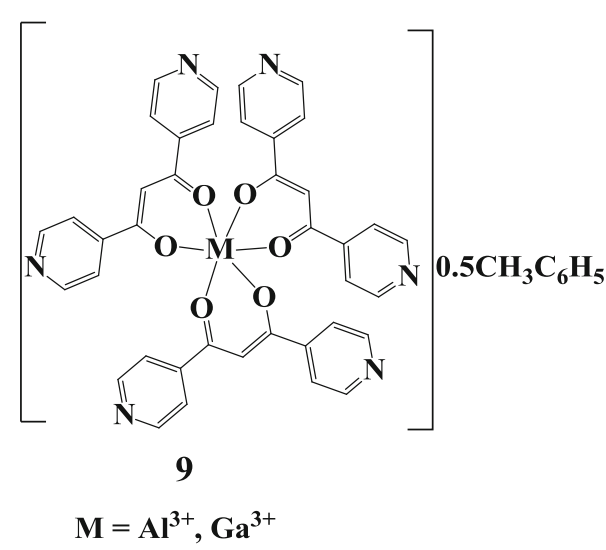

(a)

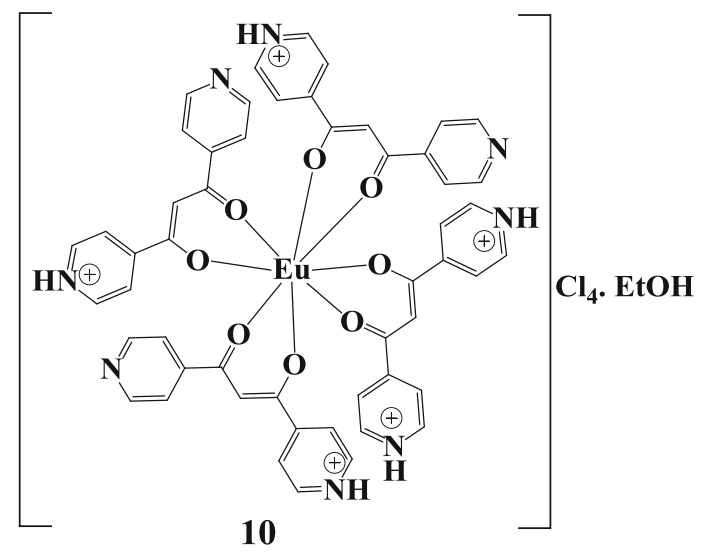

(b)

Figure 7. (a) Inclusion complex of metal $\beta$-diketonate complexes with toluene. (b) The complex $\left[\mathrm{Eu}(\mathrm{Hdpp})_{3}\left(\mathrm{H}_{2} d p p\right)\right] \mathrm{Cl}_{4} \cdot \mathrm{EtOH}$.

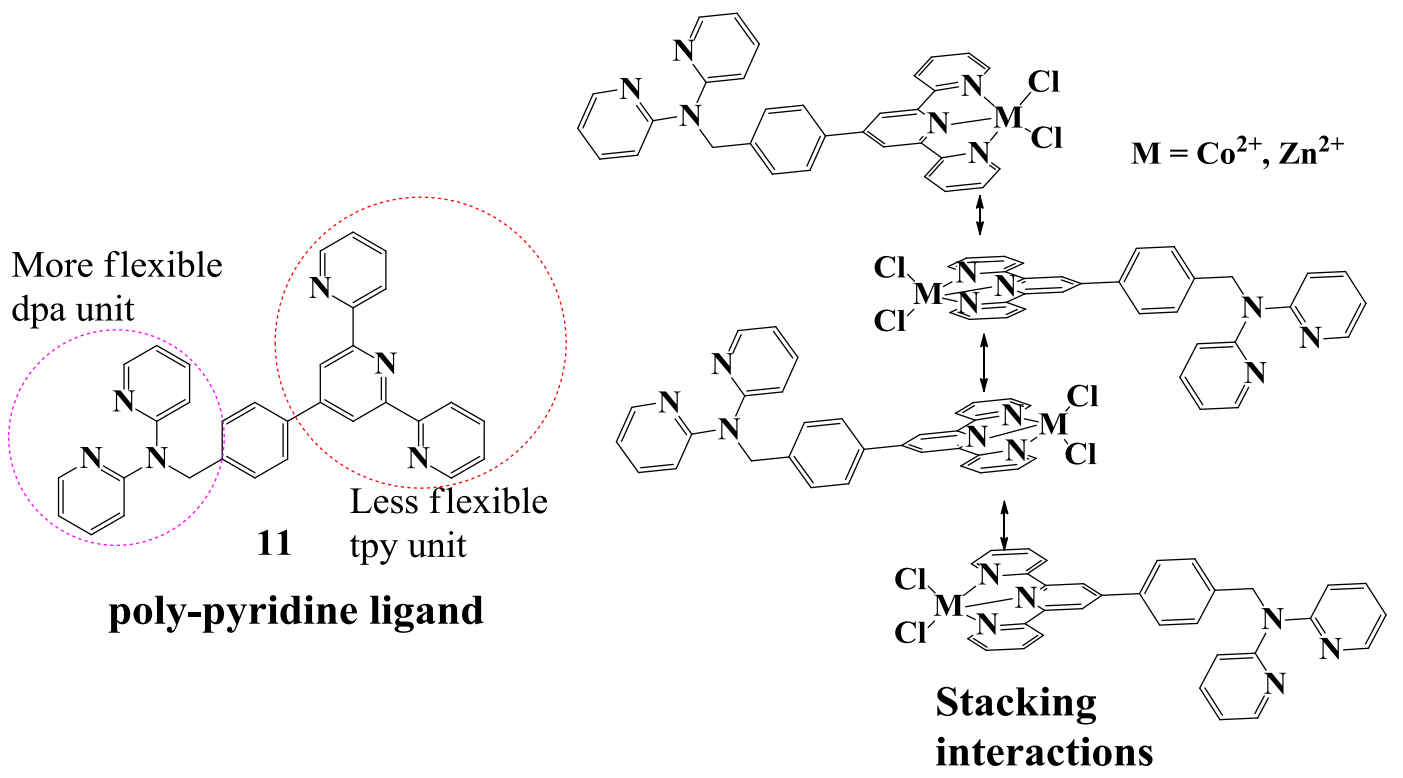

Figure 8. $\pi$-Stacking contributing to self-assembly of metal complexes of 4-\{4-[bis(2-pyridyl)aminomethyl]phenyl $\}-2,2^{\prime}: 6^{\prime}, 2^{\prime \prime}$-terpyridine.

blocks for interpenetrated primitive cubic networks of mixed-metal-organic frameworks. They form inclusion complexes with toluene. Among 1,3-di(4-pyridyl)-1,3-propan edionate containing metal complexes, europium complex has zwitterion of $H d p p$ ligand as well as a cationic $H_{2} d p p$ ligand. This is an exceptional complex among the series of other complexes of $H d p p$; it has a composition [ $\left.\mathrm{Eu}(\mathrm{Hdpp})_{3}\left(\mathrm{H}_{2} d p p\right)\right]$ $\mathrm{Cl}_{4}$.EtOH. In this complex, the partially protonated pyridyl groups form a hydrogen-bonded network. ${ }^{91}$

Self-assemblies of metal complexes $\left[\mathrm{M}(\right.$ bapt $\left.) \mathrm{Cl}_{2}\right](\mathrm{M}=$ $\mathrm{Co}^{2+}, \mathrm{Zn}^{2+}$ ) of di-topic hybrid ligand 4-\{4-[bis (2-pyridyl) aminomethyl]phenyl $\}-2,2^{\prime}: 6^{\prime}, 2^{\prime \prime}$-terpyridine (bapt) has extensive $\pi$-stacking among the tripyridine unit ${ }^{92}$ (Figure 8 ). The ligand bapt is an example of covalently linked $2,2^{\prime}: 6^{\prime}, 2^{\prime \prime}$ terpyridine (tpy) and 2, 2'-dipyridylamine ( $d p a)$ units. The lattice is primarily guided by the face-to-face arene-arene interactions and $\mathrm{C}-\mathrm{H} \cdots \mathrm{Cl}$ interactions. The $\mathrm{C}-\mathrm{H} \cdots \mathrm{Cl}$ interactions are between aromatic protons and coordinated chloride ions. The rings involved in face-to-face arene-arene interactions have centroid to centroid separations of rings as 3.5-3.7 $\AA$. One set of pyridine rings has edge to face interactions contributing to the stability of the $\pi$-stacked structure. It is interesting to note that a $\left[\mathrm{Fe}(\text { bapt })_{2}\right]\left(\mathrm{PF}_{6}\right)_{2}$, one $d p a$ site is protonated, that allows the change in electrondensity in one of the pyridine unit. Dominant interactions in the packing pattern of this complex are arene-arene interactions and aromatic $\mathrm{C}-\mathrm{H} \cdots \mathrm{F}$ hydrogen bonds. On the other hand, uncoordinated $d p a$ participate in edge-to-face and off-set face-to-face arene-arene stacking interactions. These suggest that integrity of the original stacks of ligands remains upon the change of anions in such metal complexes, the reorganization in $\pi$-interactions caused by a change in the flexible $d p a$ portion have little effect on the orientation of the less flexible tpy portion of the molecule. 
<smiles>Cc1nc[nH]c1/C=N/N=C/c1nc[nH]c1C</smiles>

12

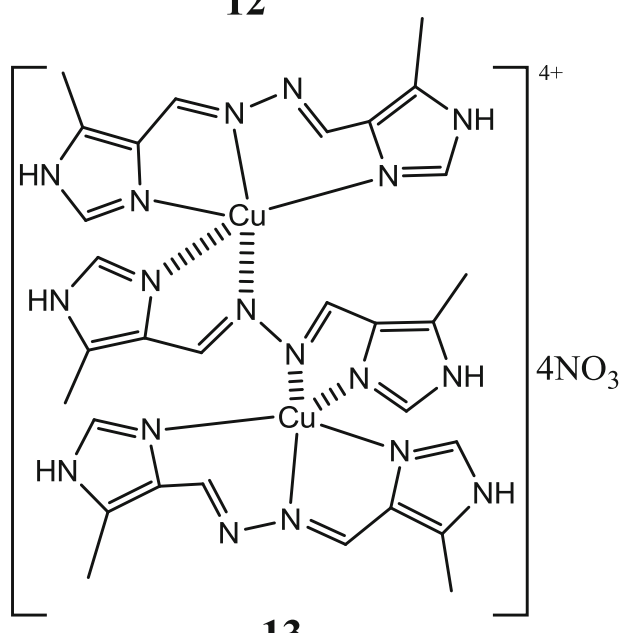

13

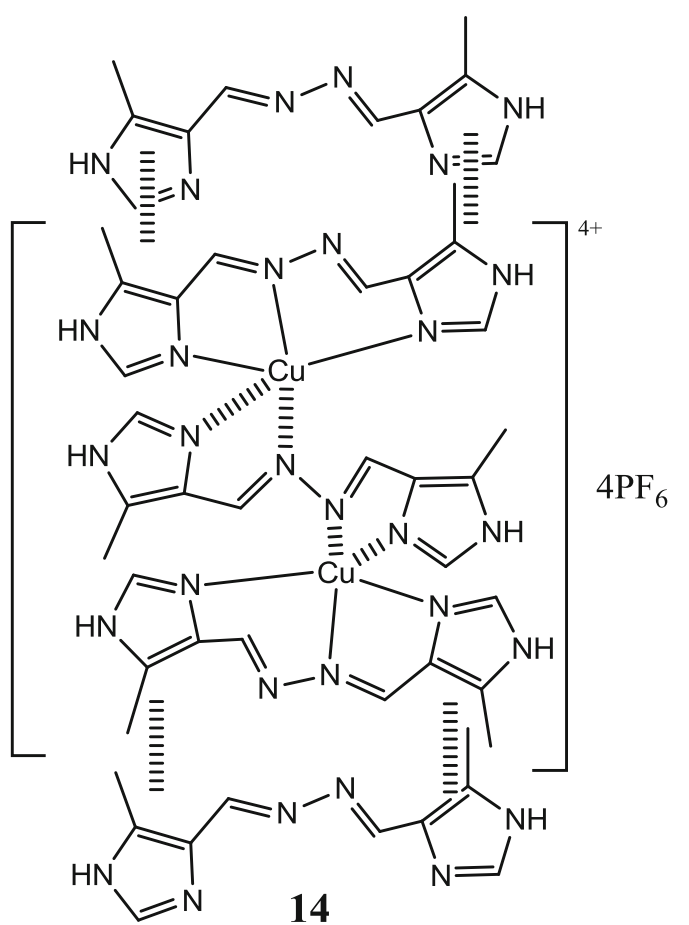

Figure 9. The anion-dependent cocrystal having $\pi$-interaction among free ligand and coordinated ligand.

Anion and complexation influencing the $\pi$-stacking pattern of a ligand is clearly reflected in self-assemblies of dinuclear copper complexes $\left[\mathrm{Cu}_{2}(\text { hmic })_{3}\right]\left(\mathrm{PF}_{6}\right)_{4} \cdot \mathrm{Hmic} \cdot 2 \mathrm{H}_{2} \mathrm{O}$ and $\left.\left[\mathrm{Cu}_{2} \text { (hmic) }\right)_{3}\right]\left(\mathrm{NO}_{3}\right)_{4} \cdot \mathrm{H}_{2} \mathrm{O}$ in which ligand abbreviated as hmic is a condensate of hydrazine and 4-methylimidazole5-carboxaldehyde. ${ }^{93}$ Both these complexes have copper ions with square pyramidal geometry in cation $\left[\mathrm{Cu}_{2}(\text { hmic })_{3}\right]^{4+}$ which is structurally centrosymmetric. Two ligands independently bind two copper ions and a third ligand acts as a bridge between to copper by complexing with each copper ion in bidentate fashion as shown in Figure 9. In $\left[\mathrm{Cu}_{2}(\text { hmic })_{3}\right]\left(\mathrm{PF}_{6}\right)_{4} \cdot$ Hmic $\cdot 2 \mathrm{H}_{2} \mathrm{O}$, the cation $\left[\mathrm{Cu}_{2}(\text { hmic })_{3}\right]^{4+}$ is sandwiched between two free ligands one of which is from the neighboring molecule. The packing of hmic has parallel $\pi$-aromatic distances $\sim 3.6 \AA$ where the stacking patterns have similarity to the coordinated ligand but such distances are less than $3.50 \AA$ in the complexes. Such a stacking does not occur in $\left[\mathrm{Cu}_{2}(\text { hmic })_{3}\right]\left(\mathrm{NO}_{3}\right)_{4} \cdot \mathrm{H}_{2} \mathrm{O}$ as it is devoid of free ligand.

Ordered supramolecular arrays of various porphyrin derivatives are built by utilizing weak interactions. ${ }^{94-102}$ In a pre-organized environment, there is no scope for solvent reorganization hence primary electron reactions are fast even at very low temperature. Non-covalent self-assemblies have orderly arranged porphyrin units. These supramolecules have been studied as functional models of biological systems capable of inducing directional motion of electrons or excitation energy through hydrogen bonding. Each porphyrin is in a defined metallation state (metal or free base). The use of free base or metalloporphyrin building blocks enables the fabrication of arrays with predetermined metallation states. When mixing two complementary porphyrin building blocks, the directed triple hydrogen bonding moiety makes it possible to form different kinds of multi-porphyrin supramolecules with different spatial relationships.

Covalently linked or non-covalently linked $\mathrm{C}_{60}$ unit to metal complexes were extensively reviewed along with their potential applications as light harvesting and advanced materials. ${ }^{103,104} \mathrm{C}_{60}$ connected to $\beta$-diketoester unit $\mathbf{1 6}$ that has long hydrophobic chain hydrocarbon at one end and at other end has ammonium cation (as depicted in Figure 10), self-assembles with zinc-porphyrin complex having crown ether 15. ${ }^{101}$ The ability of ammonium cation to bind with crown ether and zinc ion interacting with $\mathrm{C}_{60}$ generates a non-covalently linked assembly $\mathbf{1 7}$ in dichloromethane. Advantages of such non-covalent assemblies are due to the possibilities to tailor make by manipulation of reaction conditions. More recently, stable and soluble metal complexes with metal ions such as $\mathrm{Cr}(\mathrm{III}), \mathrm{Mn}(\mathrm{II}), \mathrm{Fe}(\mathrm{III}), \mathrm{Co}(\mathrm{II})$, $\mathrm{Ni}(\mathrm{II}), \mathrm{Cu}(\mathrm{II}), \mathrm{Zn}$ (II) and $\mathrm{Pd}(\mathrm{II})$ of salen-type ligand namely ( $N, N^{\prime}$-ethylenebis(salicylimine) functionalized with $\mathrm{C}_{60}$ are reported. These complexes are catalytically active for epoxidation reaction. The advantage of using these complexes as catalysts is that they can be transformed to the supported catalyst by introducing them into various $s p^{2}$-carbon nanostructures, such as nanotubes and nano-fibres. The optical properties of the fullerene derivatives differ from the parent fullerene and depending on the central metal ion these complexes show strong absorptions in the region of $400-630 \mathrm{~nm}$. The positions of such absorption are dictated by the nature of the transition metal ion. These non-covalent assemblies leave scopes to explore for their magnetic, electronic and photoactive properties. ${ }^{105}$ 


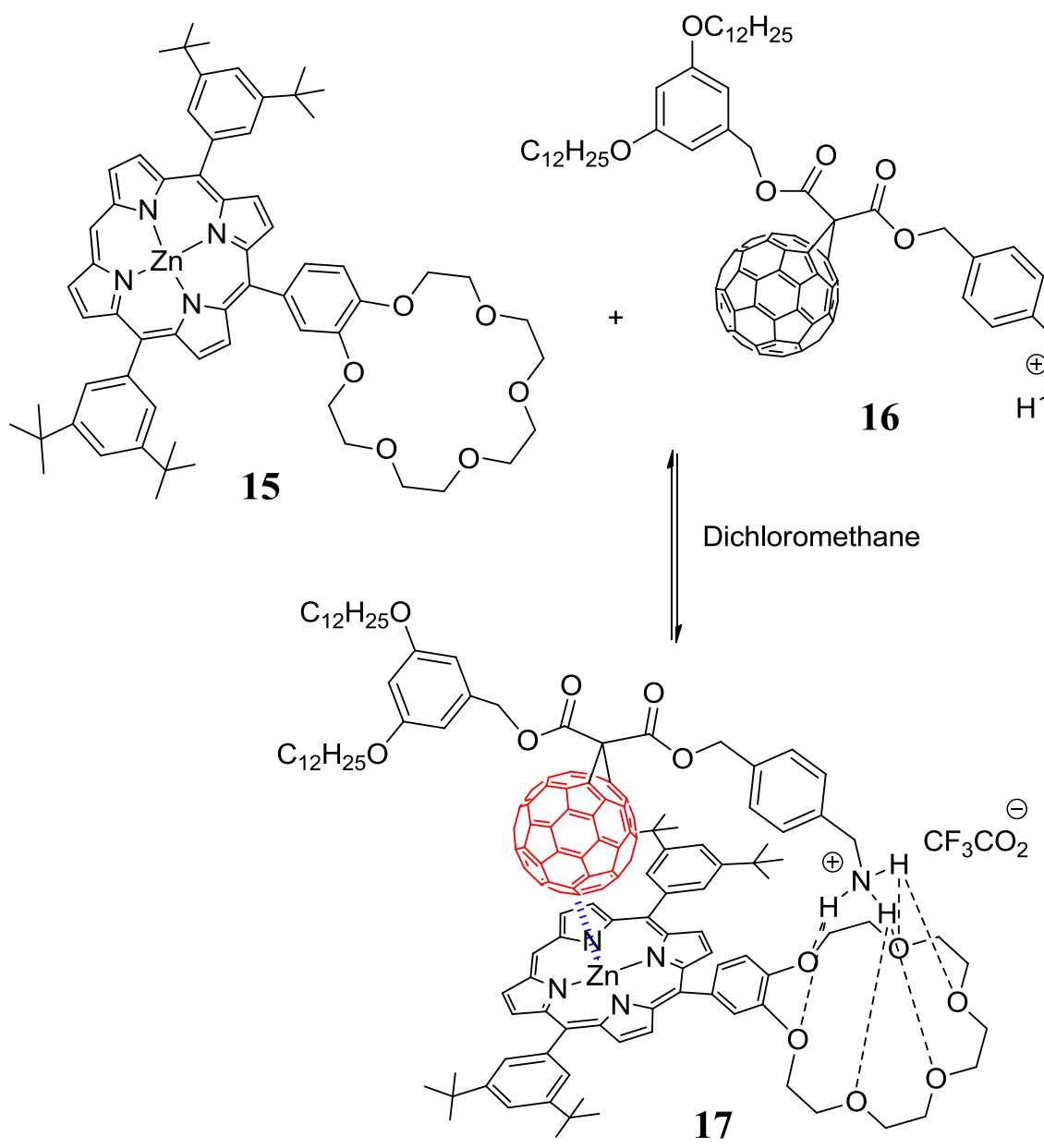

Figure 10. Weak metal- $\pi$ interactions and crown-ether-ammonium ion interactions in the self-assembly 17.

The complex 18 has uracil groups attached to the periphery of porphyrin rings; these participate in hydrogen bonds with bis(decyl)melamine (19) to form cage-like architecture. ${ }^{100}$ The hydrogen bonds between the host and guest is shown in Figure 11. Self-assembly of the porphyrin cages organizes as film of nano-meter thickness on mica surface. Decyl-hydrocarbon chains on the guest play as key players in organizing the molecules in the film. Upon formation of such assembly 20, it turns-off the electronic communication between chromophores. The loss of communication due to aggregation causes decrease in the intensity of the UV-visible absorption.

Some of the porphyrin derivatives in solid state have microporous structures. ${ }^{101}$ Self-assemblies of hydrogen-bonded poly-functionalized porphyrins having less than eight hydrogen bonds do not generate robust porous solids. But utilizing stronger intermolecular interactions and adding more ligating sites such as carboxylates on the porphyrin periphery followed by coordination to metal ion generate exceptionally robust porous solids. Such porous solids retain their internal porosity upon loss of solvates by thermal treatment.

Cyclo-metallated cationic iridium complexes having 2phenylpyridine (Hppy) and 2,2'-bipyridine (22bpy) as ancillary ligands are luminescent. In such complexes $\pi-\pi$ stacking interactions involving phenyl rings occur as face-to-face, edge-to-face and offset face-to-face. Due the repulsions between the two parallel stacked phenyl rings the face-to-face stacking is less encountered. Introduction of the intra-molecular $\pi-\pi$ stacking interactions cause distortion of the configuration of 22bpy ancillary ligands, as a result, such complexes are less photo-luminescent. For example, different fluorinated aromatic as a substituent of ligands in cationic iridium complexes control $\pi$-stacking. The complexes $\left[\operatorname{Ir}(p p y)_{2}(F 2 p h p z p y)\right] \mathrm{PF}_{6}$ and $\left[\operatorname{Ir}(\text { ppy })_{2}(F 5 p h p z p y)\right]$ $\mathrm{PF}_{6}$ where Hppy is 2-phenylpyridine, F2phpzpy is 2-(1-(3,5difluorophenyl)-1Hpyrazol-3-yl)pyridine, F5phpzpy is 2-(1pentafluorophenyl-1H-pyrazol-3-yl)-pyridine, show bluegreen emission with different efficiencies. ${ }^{106}$ From the $\pi-\pi$ distance between the centroids of the parallel aromatic rings, it is ascertained that there exists intra-molecular faceto-face $\pi-\pi$ interactions as illustrated in Figure 12. It shows that these $\pi$-interactions significantly enhance the photoluminescence efficiency of the respective complex in solution. The $\pi$-interaction is absent in the complex lacking fluorine atoms on the phenyl group, and it shows a large difference in photoluminescence property from the other complexes having $\pi$-interaction.

It is apparent that the chelate complexes, as well as complexes with macrocyclic ligands, can be suitably organized 


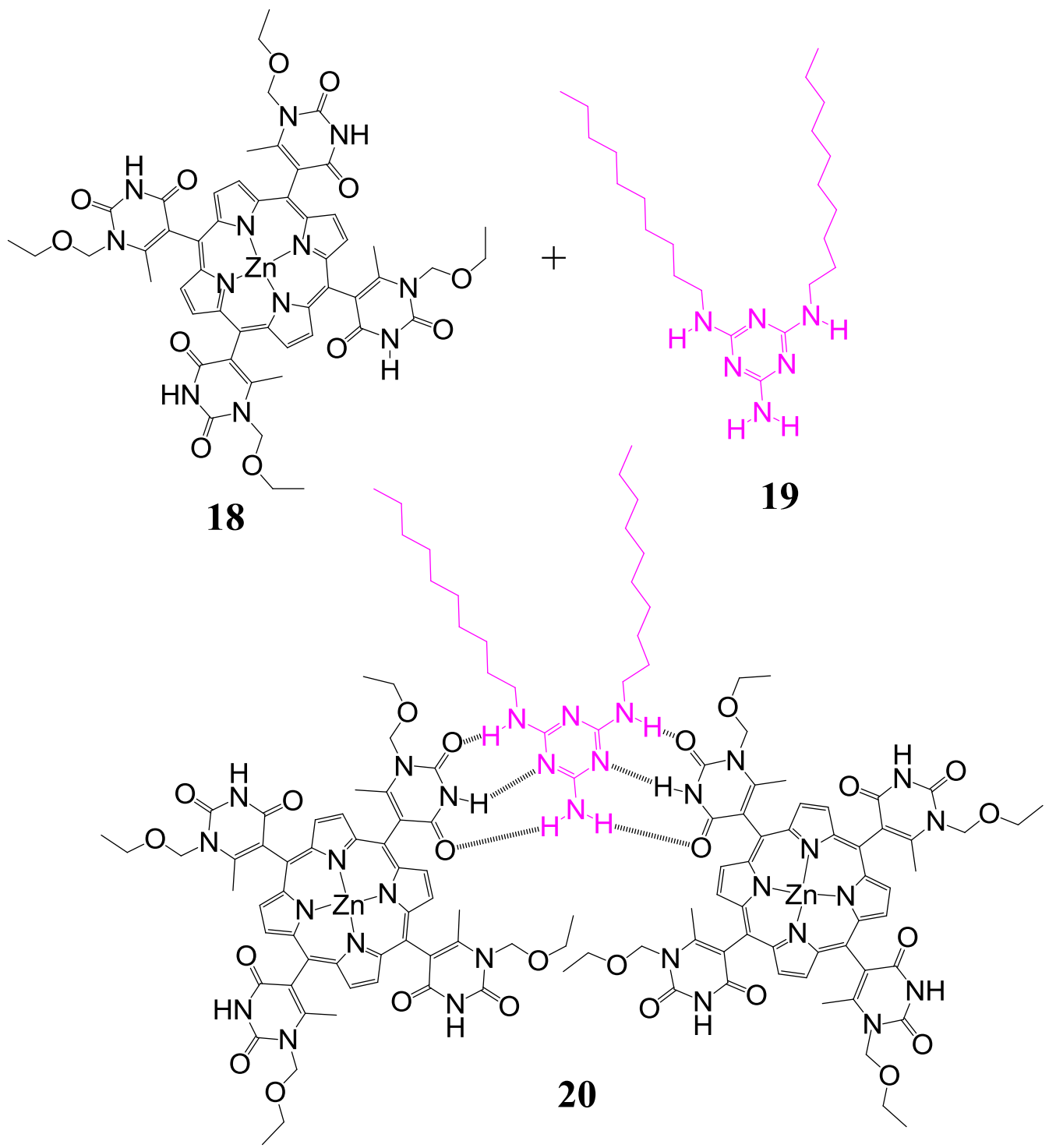

Figure 11. Self-assembly of metal porphyrin complexes by hydrogen bonds with guest molecule generating robust architecture.

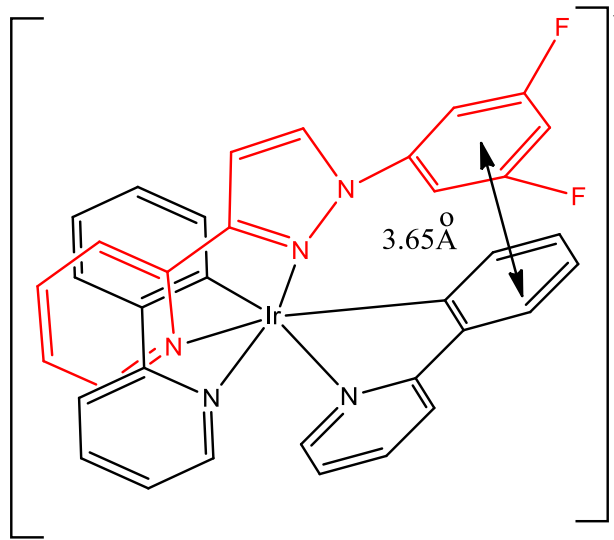

21

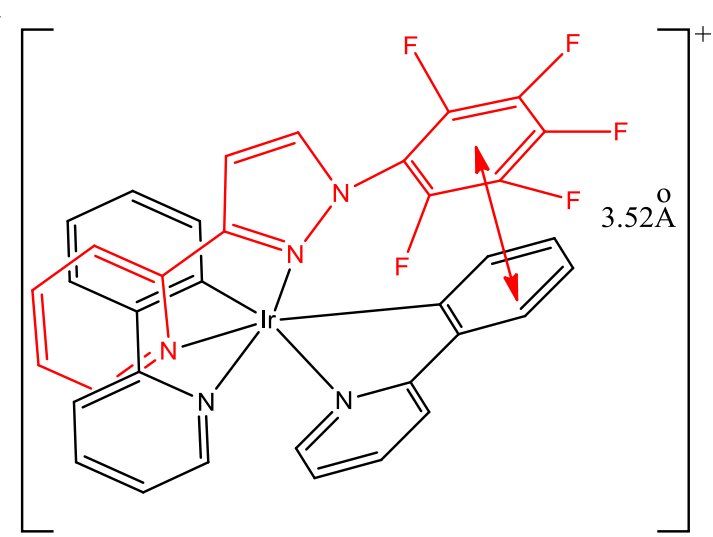

22

Figure 12. Fluorine containing aromatic units influencing intramolecular $\pi-\pi$ interactions. 
through weak $\pi$-interactions as well as ordinary stacking among the planar part of the ligands to form organized non-covalently linked assemblies. The metal complexes containing ligand connected through covalent or non-covalent interactions to robust $\pi$-donating units such as $\mathrm{C}_{60}$ can be incorporated into channels to generate novel properties and modulate catalytic activities.

\subsection{Assemblies of nucleobases in inorganic complexes}

The self-assembling of nucleobases attract attention due to the fact that self-assembling of natural DNA the replica for gene transcription occurs as a result of base stacking interactions, hydrogen bonds between bases and surrounding water molecules and in many cases through complexation. ${ }^{107,108}$ There are a large number of examples of self-assemblies of metal complexes in which the nucleobases are covalently linked to a component of the ligand that coordinates to the metal ion and the nucleobases part self-assembles to form non-covalent assemblies. There are also nucleobases which coordinate to metal ions and make new templates for self-assemblies. These aspects have been analysed in detail in a review article. ${ }^{107}$ On the other hand, the formation of guanine-quadruplex (GQ), a non-canonical nucleic acid structure, requires monovalent metal ions. ${ }^{109}$ Guanine-quadruplex comprises of hydrogenbonded self-assemblies involving four guanines to adopt a square planar tetrad. To form such tetrads $\mathbf{2 3}$, guanine molecules act as hydrogen bond donors as well as acceptors (Figure 13). Multiple number of G-tetrads generally stack to form the guanine-quadruplex assisted by alkali metal ions such as potassium or sodium. Different conformations, and also depending on a number of nucleic acid molecules, they adopt varieties of topologies. Self-association in solution and at the interface of solid and liquid of ferrocene-tethered guanosine derivatives are used to prepare G-ribbons and lamellar G-dimers. In these cases, physisorption affects the formation of the supramolecular assemblies and for such assembling processes metal ions are not necessarily required. ${ }^{110}$ Since the above-mentioned assemblies are systematically analyzed in review articles, ${ }^{107,111}$ the discussion here is limited to specific aspects of self-assemblies of metal complexes that control the self-assemblies of free nucleobases within their non-covlaent assemblies. Such assemblies generate impetus to modulate and stabilize sub-assemblies of different sizes and shape or guide the assemblies of nucleobases within the assembly in a designed manner. The discrete units of protonated and unprotonated as well as hydrated or self-assembled units of nucleobases get encapsulated in various self-assemblies of inorganic complexes. Metal oxalates are widely studied as supramolecular building blocks that are known to stabilise unusual self-assemblies of protonated nucleobases. ${ }^{112,113}$ Theoretical calculations on different types of hydrogenbonded synthons 25-28 between adeninium cations with

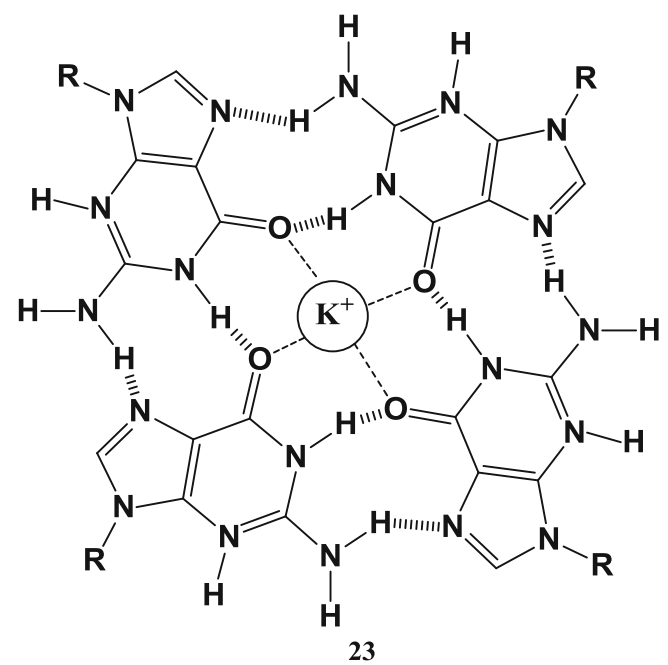

Figure 13. Interaction of potassium ion with four non-covalently linked Guanines found in G-quartet.

copper-oxalate dianion have revealed that there are differences in energy up to a magnitude of $12 \mathrm{kcal} / \mathrm{mol}$ (Figure 14a) among the different experimentally observed synthons. Such an energy difference is comparable to the solute-solvent interactions, and hence are tunable by controlling the preparation methodologies from the same substrate combinations. In practice, the copper oxalate complexes having adeninium cations is comprised of a chain of dications held each other by hydrogen bonds. Such chain-like structures are located in between the layers of copperoxalate complex anions. In these self-assemblies, synthons connecting the anions and cations are not the lowest energy synthon 25 involving carboxylate oxygen atoms of two carboxylates. The observed synthons are formed by the two oxygen of one carboxylate group $\mathbf{2 6}$ as illustrated in Figure 14c. This is a clear evidence of synthon competition and it is a common feature in multi-component cocrystals. In this particular example, the self-assembly 31 has the 1H, 9H-adeninium cation (29). Density functional theory calculation shows that $1 \mathrm{H}, 9 \mathrm{H}$-adeninium cation (29) is the most stable form followed by $3 \mathrm{H}, 7 \mathrm{H}-$ adeninium cation (30) by an energy difference of 0.46 $\mathrm{kcal} / \mathrm{mol}{ }^{114}$

Changing the anionic part of complex influences supramolecular features and self-assemblies of adeninium cation. ${ }^{115}$ The position of protonation of adenine can be modulated at different acceptor sites in self-assembled structures. For example, ribbon-like structures (33) comprising of pairs of differently protonated adeninium cations positioned next to each other. The adeninium cation protonated to have hydrogen atoms at 1- and 9-positions of adenine (29) forms hydrogen bonds with another adeninium cation having hydrogen atoms at 3- and 7-positions of adenine (30). These hydrogen bonded pairs of cations are held to copper(II) or manganese(II) bis-2,6-pyridinedicarboxylate complex 32 (Figure 15a) through bifurcated hydrogen bonds. This example is a clear indication how the synthon variations 
<smiles></smiles>

OKcal $/ \mathrm{mol}$

25

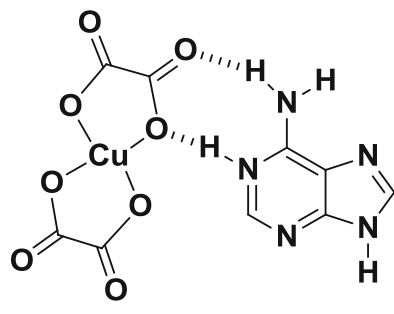

$+3.84 \mathrm{Kcal} / \mathrm{mol}$

26

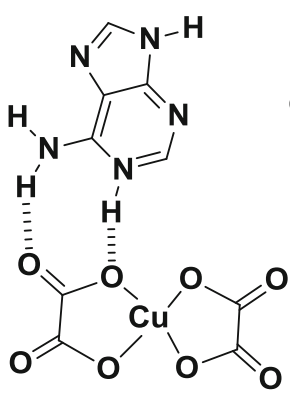

27

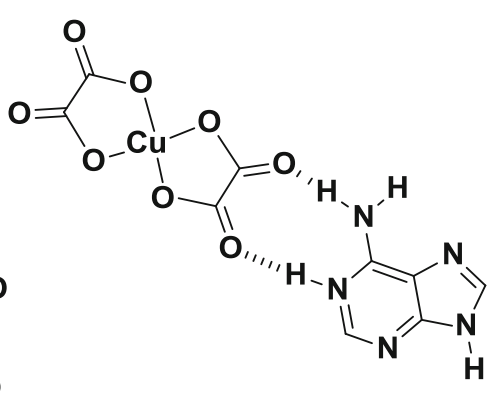

$+12.06 \mathrm{Kcal} / \mathrm{mol}$

(a)<smiles></smiles>

29

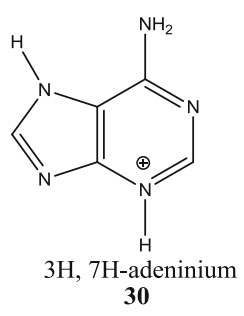

(b)

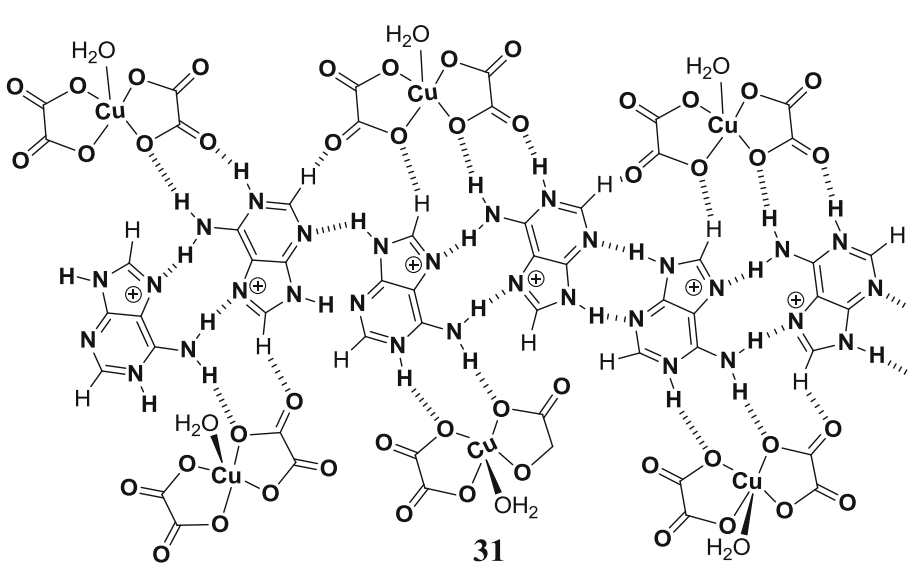

(c)

Figure 14. (a) Some possible hydrogen bonded synthons of copper(II) bis-oxalate with adeninium cation; (b) two different types of adeninium cations; (c) experimentally observed self-assembly of the $1 \mathrm{H}, 9 \mathrm{H}$-adeninium cations held by aqua-copper(II) bis-oxalate anions.

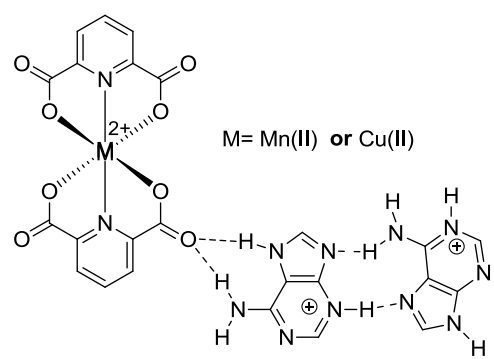

(a)

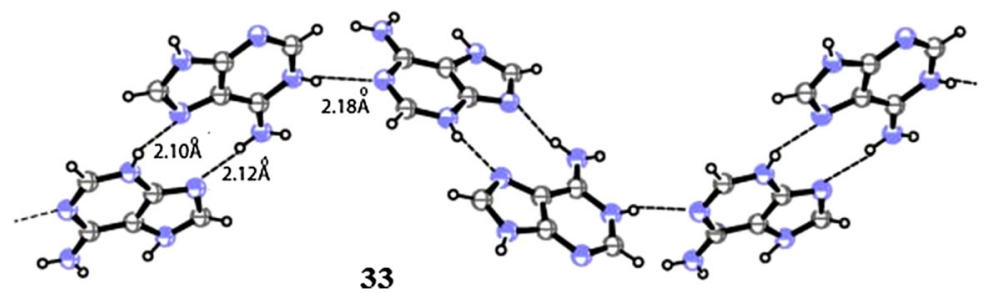

(b)

Figure 15. (a) Manganese(II) or cobalt(II) bis-2,6-pyridinedicarboxylate complex having two adeninium cations that are protonated at dissimilar positions. (b) Ribbon-like hydrogen bonded structure formed by adeninium cations.

take place by changing anions of the anionic complex to stabilize assemblies of adeninium cations that are protonated at dissimilar positions.

Divalent metal-oxalate complexes with cytosinium cations $(\mathrm{Hcyt})_{2}\left[\mathrm{M}(\mathrm{ox})_{2}\left(\mathrm{H}_{2} \mathrm{O}\right)_{2}\right]$ [where cyt = cytosine; $\mathrm{M}=$ divalent $\mathrm{Mn}, \mathrm{Co}, \mathrm{Cu}$ or $\mathrm{Zn}$ ion] exhibits ribbon-like $1 \mathrm{D}$ hydrogen bonded cytosinium cations held within anionic layers formed by metal oxalate anions. The self-assemblies of cytosinium cations are formed by a hydrogen bond between $\mathrm{C}=\mathrm{O}$ and amine group of adjacent cytosinium cations. ${ }^{116}$ Cytosinium aqua-manganese(II) bis-pyridinedicarboxylate complex $\left[\mathrm{H}_{2} c y t\right]_{2}\left[\mathrm{Mn}(p d c)_{2}\left(\mathrm{H}_{2} \mathrm{O}\right)\right] \cdot(c y t)_{2} \cdot 6 \mathrm{H}_{2} \mathrm{O}$ (where $p d c$ $=2,6$-pyridinedicarboxylate) is an exceptional example of host-guest complex having cytosinium cation and neutral 


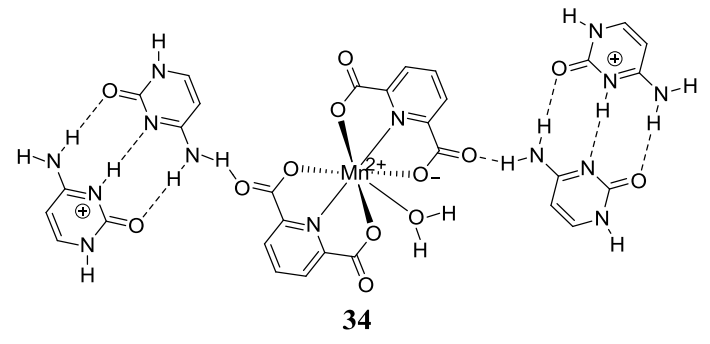

(a)

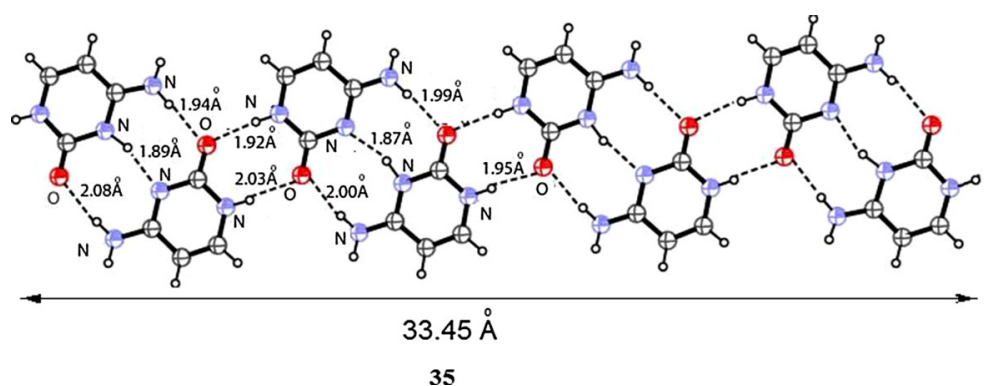

(b)

Figure 16. (a) Host-guest complex of cytosinium aqua-manganese(II) bis-pyridinedicarboxylate with cytosine. (b) Tetrameric cytosine-cytosinium ribbons in the complex.

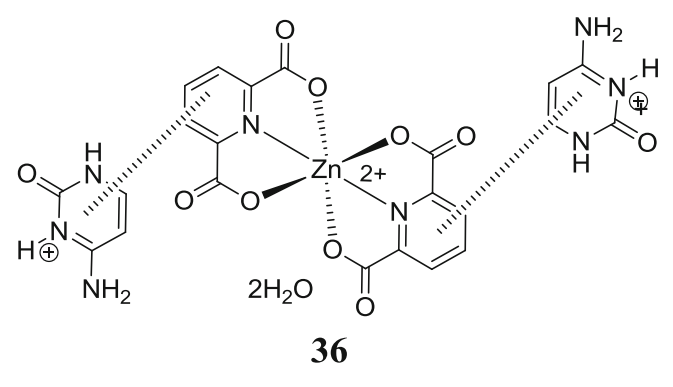

(a)
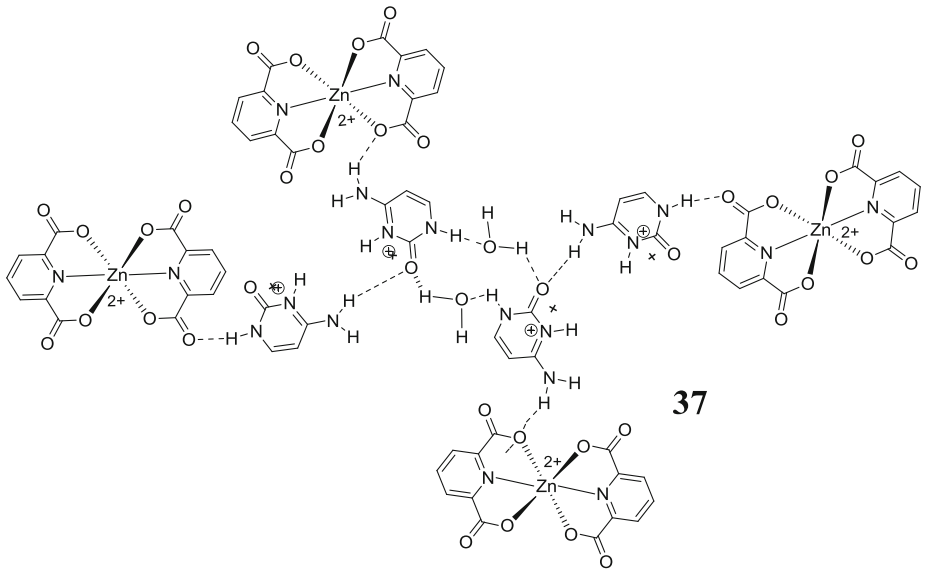

37

Figure 17. (a) Cytosinium zinc(II) 2,6-pyridinedicarboxylate dihydrate. (b) Zinc(II) bis-2,6-pyridinedicarboxylate dianions flanking water-assisted assembly of cytosinium cations.

cytosine molecule. ${ }^{117}$ Each cytosinium cation has hydrogen atoms at 1- and 3-positions. The manganese complex 34 has a pentagonal bipyramidal seven coordinated geometry having two $p d c$ ligands and a water molecule attached to manganese(II) ion (Figure 16a). Cytosine molecules form hydrogen bonds to cytosinium cations to form hydrogen-bonded dimers, and four units of Cyt.Hcyt ${ }^{+}$ such adjacent dimers are held together by hydrogen bonds forming tetrameric ribbons $\mathbf{3 5}$. These ribbons of length 33.45 $\AA$ are formed by hydrogen bonds between neutral and protonated cytosine entities next to each other (Figure 16b). The manganese complex thus provides a means for guest accommodation through interactions of cations of the guest with neutral guests. A similar complex having neutral and protonated cytosine is $(\mathrm{Hcyt})\left[\mathrm{Ni}(\mathrm{nta})\left(\mathrm{H}_{2} \mathrm{O}\right)_{2}\right] \cdot(\mathrm{cyt}) \cdot 2 \mathrm{H}_{2} \mathrm{O}$ (where $n t a=$ nitrilotriacetate). ${ }^{118}$ In this example, dimers reunite by hydrogen bonds, and form an infinite tape-like molecular sheet that passes through the layer-like assembly of $\left[\mathrm{Ni}(n t a)\left(\mathrm{H}_{2} \mathrm{O}\right)_{2}\right]^{-}$anions. These two examples show the possibilities of having self-assemblies of neutral cytosine molecules and protonated cytosine cations as infinite chains or as structures of definite dimension within layers of complex anions.

Water also assists in stabilizing hydrogen-bonded cyclic assemblies of cytosinium cations in metal complexes. For example, cytosinium zinc(II) bis-2,6-pyridinedicarboxylate dihydrate has two cytosinium cations stacked parallel to the aromatic ring of pyridinedicarboxylate ligands (Figure 17a). The self-assembly of the cationic part has hydrogenbonded cyclic sub-assemblies, each sub-assembly comprising of two water molecules bridging two cytosinium cations (Figure 17b) through $\mathrm{C}=\mathrm{O} \cdots \mathrm{H}$ and $\mathrm{N}-\mathrm{H} \cdots \mathrm{O}$ hydrogen bonds. These cyclic sub-assemblies are connected to two cytosinium cations which are hydrogen bonded to $\mathrm{Zn}$ (II)$p d c$ anion. Sub-assembly may be considered as an extension of non-covalent synthons expanding domain to provide new replicas within a self-assembly. These aquated domain expanded cationic sub-assemblies are flanked by zinc(II) 2,6-pyridinedicarboxylate anions. ${ }^{119}$ These examples clearly suggest that the type and oxidation state of metal ions, as 


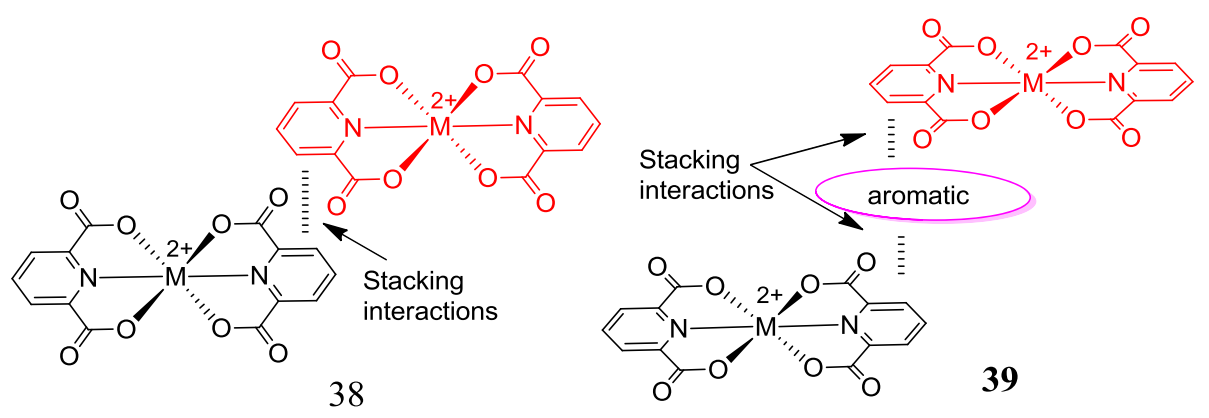

(a)

(b)

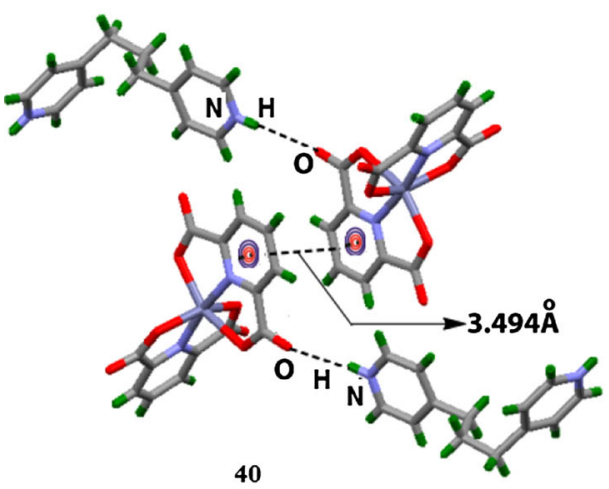

(c)

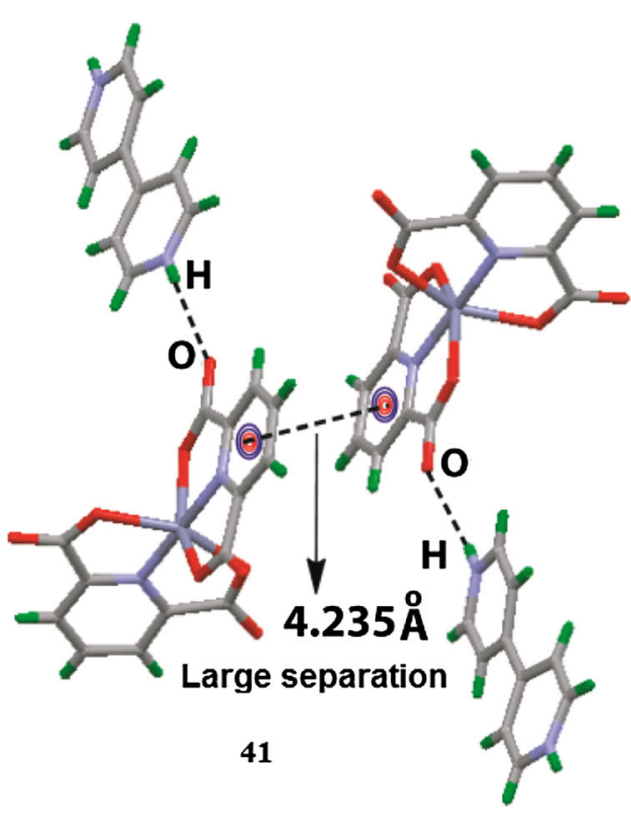

(d)

Figure 18. (a) and (b) are two ways to have stack between metal 2,6-pyridinedicarboxylates with or without an intervening aromatic unit; (c) and (d) are two representative examples.

well as the type of ligands on the metal ions, controls the self-assembling properties of nucleobases. Thus, metal complexes have a bigger role to provide the directional architectures with site-specific protonation, hence the above examples may be a useful guide to study the properties of such assemblies, requiring further attention.

\subsection{Stacking interactions in host-guest complexes}

Chelate-chelate interactions associated with many metal complexes contribute to self- assembling. ${ }^{120}$ There exists ample scope to modulate stacking arrangements in metal chelates through different stimulants such as solvents, counter ions, guests and reaction conditions. These aspects are reflected in self-assembling of metal- $p d c$ complexes. $\pi$-Stacking interactions among the chelating ligands are prominent in self-assemblies of metal 2,6-pyridinedicarboxylate complexes. They adopt chain-like structures as illustrated in Figure 18a, where the aromatic parts of two independent $p d c$ ligands from neighboring anions are positioned parallel over each other with or without a planar spacer molecule. Such structures are found in zinc(II) 2,6-pyridinedicarboxylate complexes with different pyridinium cations. For example, the complex $\left[\mathrm{H}_{2}\right.$ tmbpy] $\left[\mathrm{Zn}(p d c)_{2}\right] \cdot 5 \mathrm{H}_{2} \mathrm{O}$ has packing pattern like in 38; whereas the complex $\left[\mathrm{H}_{2} 44 b p y\right]\left[\mathrm{Zn}(p d c)_{2}\right] \cdot 6 \mathrm{H}_{2} \mathrm{O}$ has packing similar to $\mathbf{3 9}$ of Figure 18a (Where, tmbpy $=$ trimethylenebipyridine $44 b p y=4,4^{\prime}$-bipyridine). ${ }^{121}$ The $\pi$-separation between the pyridine rings of $\left[\mathrm{Zn}(p d c)_{2}\right]^{2-}$ in complex $\left[\mathrm{H}_{2}\right.$ bpy] $\left[\mathrm{Zn}(p d c)_{2}\right] \cdot 6 \mathrm{H}_{2} \mathrm{O}$ is $\sim 4.2 \AA$ which is $\sim 3.5 \AA$ in $\left[\mathrm{H}_{2}\right.$ tmbpy] $\left[\mathrm{Zn}(p d c)_{2}\right] \cdot 5 \mathrm{H}_{2} \mathrm{O}$ (Figure $18 \mathrm{c}$ and d). Both these complexes on heating transform to zinc oxide, but decomposition temperatures are different; namely, $\mathrm{H}_{2}$ tmbpy] $\left[\mathrm{Zn}(p d c)_{2}\right] \cdot 5 \mathrm{H}_{2} \mathrm{O}$ decomposes at $425^{\circ} \mathrm{C}$ whereas $\left[\mathrm{H}_{2}\right.$ bpy $]\left[\mathrm{Zn}(p d c)_{2}\right] \cdot 6 \mathrm{H}_{2} \mathrm{O}$, at $380^{\circ} \mathrm{C}$. The higher thermal stability of the complex $\left[\mathrm{H}_{2}\right.$ tmbpy] $\left[\mathrm{Zn}(p d c)_{2}\right] \cdot 5 \mathrm{H}_{2} \mathrm{O}$ is attributed to strong $\pi$-stacking interactions in this complex.

Host-guest complexes of these two complexes with 2,7dihydroxynaphthalene $(2,7 \mathrm{dhn})$ have striking differences 


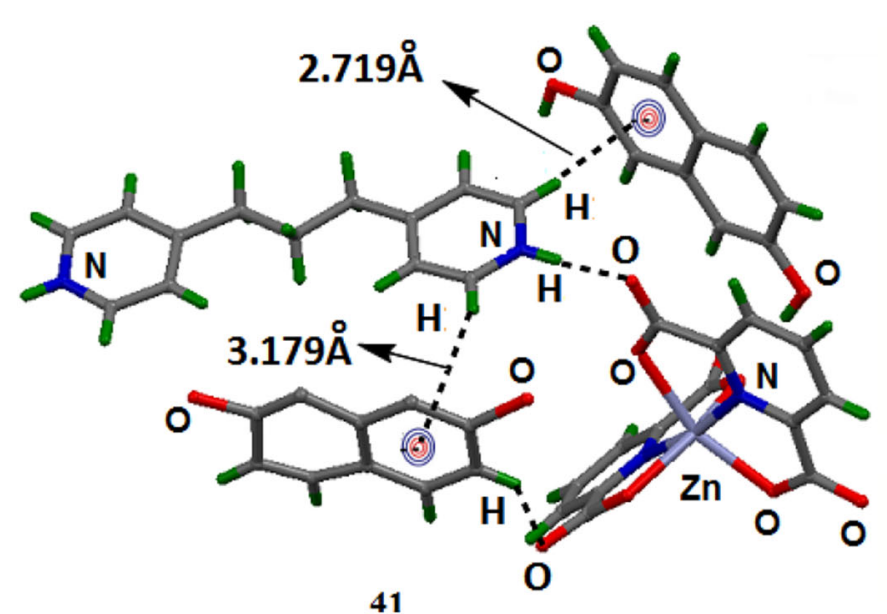

(a)

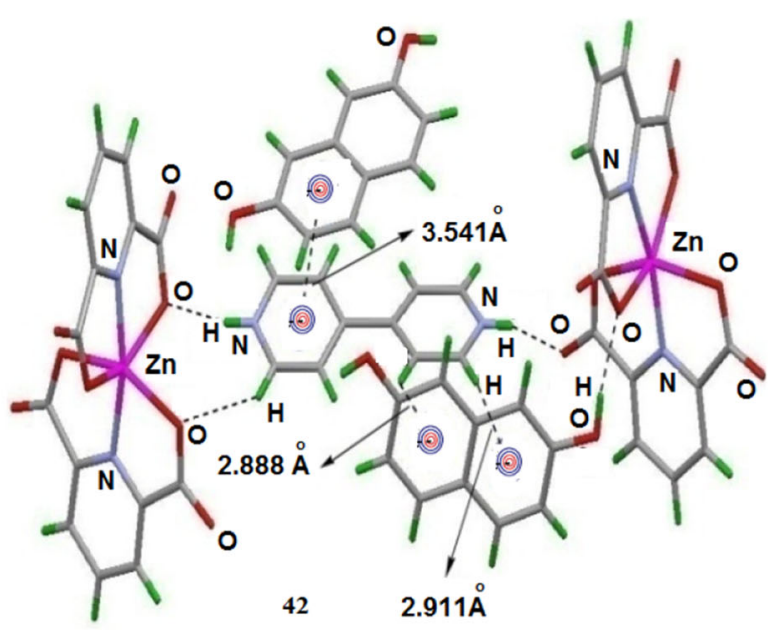

(b)

Figure 19. Interactions between cations, anions, and guest molecules. (a) $\left[\mathrm{H}_{2}\right.$ tmbpy] $\left.\mathrm{Zn}(p d c)_{2}\right] \cdot 4(2,7 d h n) \cdot 3 \mathrm{H}_{2} \mathrm{O}(\mathrm{in}$ one of the 2,7-naphthslenediol ring hydrogen atoms were not located in X-ray structure); (b) $\left[\mathrm{H}_{2} 44 b p y\right]\left[\mathrm{Zn}(p d c)_{2}\right] \cdot 2(2,7 d h n) \cdot 5 \mathrm{H}_{2} \mathrm{O}$.

Host-guest interactions

$$
\begin{aligned}
& \left(\mathrm{H}_{2} 44 b p p y\right)\left[\mathrm{Co}(p d c)_{2}\right]+\mathrm{G} \stackrel{\mathrm{K}_{1}}{\rightleftharpoons}\left(\mathrm{H}_{2} 44 b p y\right)\left[\mathrm{Co}(p d c)_{2}\right] . \mathrm{G} \\
& \text { Exchange of proton of bipyridinium cations to form template } \\
& \left\{\left(\mathrm{H}_{2} 44 b p y\right)\left[\mathrm{Co}(p d c)_{2}\right] . \mathrm{G}\right\}+\mathrm{H}_{2} 44 b p p y+\mathrm{G} \stackrel{\mathrm{K}_{2}}{\rightleftharpoons}\left\{(\mathrm{H} 44 b p y)\left(\mathrm{H}_{2} 44 b p y\right)_{0.5}\left[\mathrm{Co}(p d c)_{2}\right]\right\} .2(\mathrm{G}) \\
& \text { Next guest inclusion } \\
& \left\{(\mathrm{H} 44 b p y)\left(\mathrm{H}_{2} 44 b p y\right)_{0.5}\left[\mathrm{Co}(\mathrm{pdc})_{2}\right]\right\} .2(\mathrm{G})+\mathrm{G} \stackrel{\mathrm{K}_{3}}{\rightleftharpoons}\left\{(\mathrm{H} 44 b p y)\left(\mathrm{H}_{2} 44 b p y\right)_{0.5}\left[\mathrm{Co}(p d c)_{2}\right]\right\} .3(\mathrm{G} .) \\
& \mathrm{G}=\mathrm{Guest} ; 44 b p y=4,4^{\prime} \text {-bipyridine }
\end{aligned}
$$

Scheme 1. Different host-guest equilibriums to enhance guest encapsulation.

between them. Though structures of the two complexes are based on identical anions, the difference in the cations causes a different amount of uptake of guest molecules. The amounts of guest dihydroxynaphthalene with respect to per metal ion are 1:2 in complex $\mathbf{4 1}$ and 1:4 in complex $\mathbf{4 2}$ (Figure 19). Weak $\mathrm{C}-\mathrm{H} \cdots \pi$ interaction is involved in the complex having $\mathrm{H}_{2}$ tmbpy cations whereas the other complex is guided by $\pi-\pi$ interactions between the guest molecules and cations. In the host-guest complex [ $\left.\mathrm{H}_{2} 44 b p y\right]\left[\mathrm{Zn}(p d c)_{2}\right] \cdot 2(2,7 d h n)$. $5 \mathrm{H}_{2} \mathrm{O}$ dihydroxynaphthalene rings are stacked over each other and have $\pi$-interactions among them. The centroid-tocentroid distance between the ring of naphthalenediol and the ring of a $4,4^{\prime}$-bipyridinium cation is $3.54 \AA$. Both the host-guest complexes form to zinc oxide upon heating; the complex $\mathbf{4 1}$ forms zinc oxide at $400^{\circ}$ and whereas the complex 42 decomposes to zinc oxide at $460^{\circ} \mathrm{C}$. This result also shows that complex having higher thermal stability has $\pi$ stacks whereas the other does not but has weak $\mathrm{C}-\mathrm{H} \cdots \pi$ interactions.
A recent study ${ }^{122}$ has revealed that the extent of protonation of the organocation derived from bipyridine controls the uptake of phenolic guest molecules in cobalt(II) 2,6pyridinedicarboxylate complex. 4,4'-Bipyridinium cobalt(II) 2,6-pyridinedicarboxylate hexahydrate forms host-guest complexes with 2,3- or 2,7-dihydroxynaphthalene (guests are abbreviated as $23 d h n$ and $27 d h n$, respectively, and 44bpy is $4,4^{\prime}$ bipyridine). The compositions of host-guest complexes are different. This difference is explained by the protonation equilibrium guiding guest inclusion process through various template formations as shown in Scheme 1.

In this Scheme, three sets of equilibriums are suggested in which the inclusion of the first guest is just through the host and guest interactions. Whereas, second equilibrium is a reorganization of the host through a protonationdeprotonation scheme of the cation involving accommodation of another guest. In the third step, the modified hostguest complex formed in the second step takes up another guest molecule. From isothermal calorimetry, the binding 


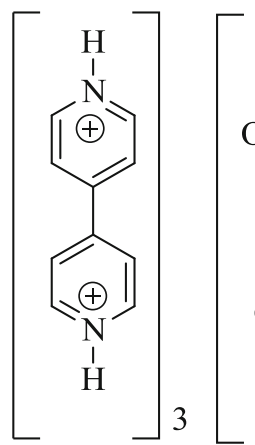

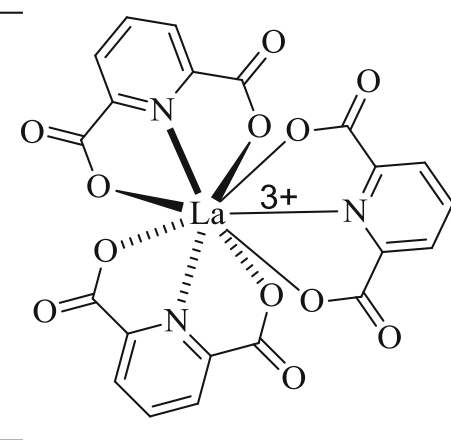

43
$15 \mathrm{H}_{2} \mathrm{O}$

2

lanthanum tris

Figure 20. 4,4'-Bipyridinium 2,6-pyridinedicarboxylate.

constants for these three steps in the inclusion of 23dhn guest, $\mathrm{K}_{1}>\mathrm{K}_{2} \approx \mathrm{K}_{3}$ whereas for a similar process with $27 \mathrm{dhn}$, $\mathrm{K}_{1} \approx \mathrm{K}_{3}>\mathrm{K}_{2}$. Accordingly, in the case of 27dhn a hostguest complex $\left(\mathrm{H}_{2} 44 b p y\right)\left[\mathrm{Co}(p d c)_{2}\right] \cdot 3(27 d h n) \cdot 6\left(\mathrm{H}_{2} \mathrm{O}\right)$ was observed. Whereas in the case of $27 d n h$ as a guest, the driving force of the reaction was towards the third step, hence host-guest complex of $\left[(\mathrm{H} 44 b p y)\left(\mathrm{H}_{2} 44 b p y\right)_{0.5}\left[\mathrm{Co}(p d c)_{2}\right]\right.$. $\left.3(23 d h n) \cdot 3\left(\mathrm{H}_{2} \mathrm{O}\right)\right]_{2}$ was observed.

Lanthanum tris-2,6-pyridinedicarboxylate complex $\mathbf{4 3}$ (Figure 20) acts as a host for positional isomers 2,3-dihydroxynaphthalene and 2,7-dihydroxynaphthalene. The corresponding host-guest complexes are $\left(\mathrm{H}_{2} 44 b p y\right)_{3}[\mathrm{La}$ $\left.(p d c)_{3}\right]_{2} \cdot 3(23 d h n) \cdot 19 \mathrm{H}_{2} \mathrm{O}, \quad\left(\mathrm{H}_{2} 44 b p y\right)_{1.5}\left[\mathrm{La}(p d c)_{3}\right] \cdot 3$ $(27 d h n) \cdot 10 \mathrm{H}_{2} \mathrm{O} .{ }^{123}$ Analysis of structures have shown that the interactions between the anions interacting with cations to hold 2,3- or 2,7-naphthalenediols in $\mathbf{4 4}$ and $\mathbf{4 5}$ have close similarity. In such host templates, two lanthanum tris-pdc anions are bridged by hydrogen bonding with one 4,4'-bipyridinium cation. These templates hold the naphthalenediol guest molecules, and the weak interaction schemes in each case are different (Figure 21). These results indicate that changing the anionic template from $b i s-p d c$ to $t r i s-p d c$ and changing the central metal ion from cobalt to lanthanum, the intake of guest molecule changes, but the nature of guest has an influence to decide the uptake of a number of guest per host molecule.

\subsection{Coordination effect of ligand and effect of substituent on ligands in self-assembling}

There are a large number of ways in which a 2,6-pyridinedi carboxylate can bind to metal ions as shown in Figure 22. These modes provide versatility to prepare different templates in respective self-assemblies ${ }^{124-127}$ for binding to guest molecules. Major portions of this class of metal complexes have binding mode I (Figure 22), on the other hand, the coordination modes VI-VII are observed only under constraint conditions.

Ethtylenediammonium nickel(II) complex, [ $\mathrm{H}_{2}$ en $]$ $\left[\mathrm{Ni}(p d c)_{2}\right] \cdot 2 \mathrm{H}_{2} \mathrm{O}$ (en = ethylenediamine) is a conventional 2,6-pyridinedicarboxylate complex. ${ }^{128}$ It forms layerlike structure with interlayer separation $8.2 \AA$ (Figure 23a). Whereas, similar copper complex is a mixed cationic complex having ethylenediammonium dications and also having chelating neutral ethylenediamine with a composition $\left[\mathrm{H}_{2} e n\right]\left[\mathrm{Cu}(e n)_{2}\left(\mathrm{H}_{2} \mathrm{O}\right)_{2}\right] \cdot\left[\mathrm{Cu}(p d c)_{2}\right]_{2} \cdot \mathrm{H}_{2} \mathrm{O}$. Interesting aspect of the complexes is the layer-like structure of copper(II) bis-2,6-pyridinedicarboxylate anions encapsulates the bis-ethylenediamine copper(II) complex cations. Each complex cation is surrounded by for anions and two water molecules which form hydrogen bonds to the anionic part

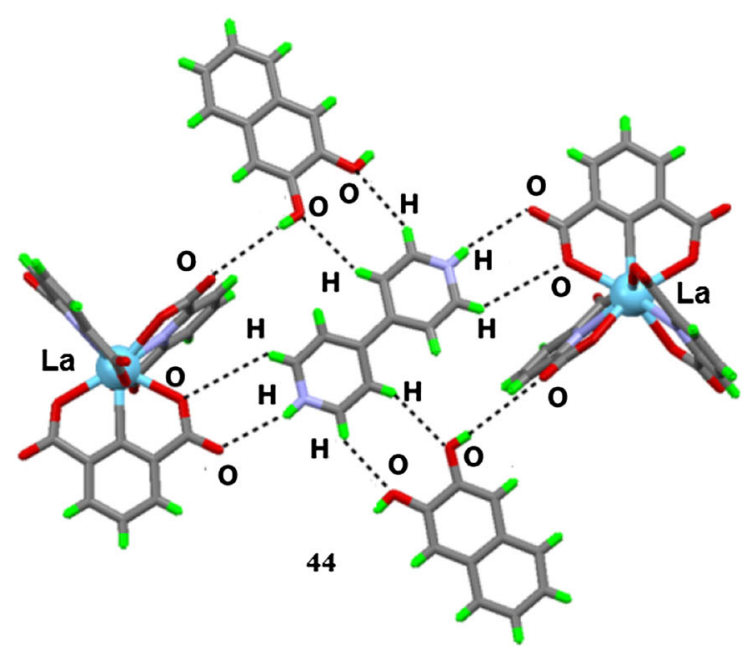

(a)

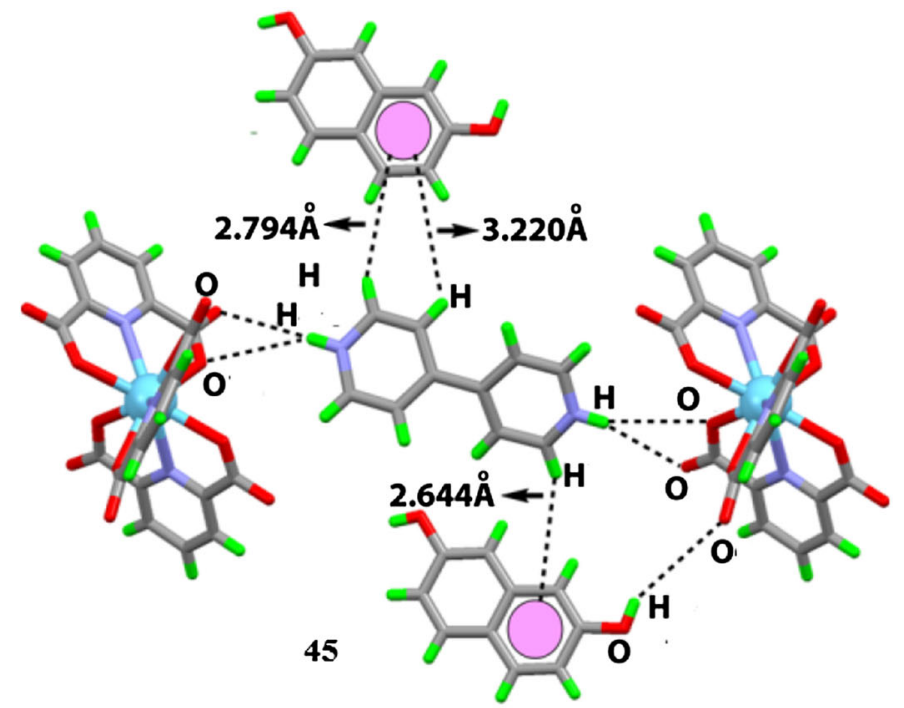

(b)

Figure 21. (a) 2,3-Dihydroxynaphthalene; (b) 2,7-dihydroxynaphthalene in respective host-guest complex with 4,4'-bipyridinium lanthanum tris 2,6-pyridinedicarboxylate. 
<smiles>[M]OC(=O)c1cccc(C(=O)OC)n1</smiles>

I<smiles></smiles>

V<smiles></smiles><smiles></smiles>

III<smiles></smiles>

VI

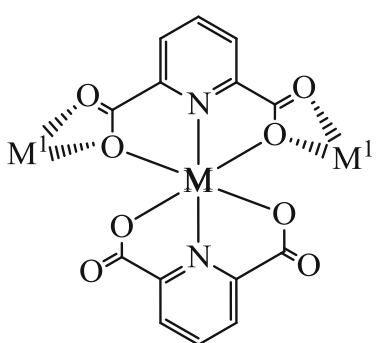

VII<smiles></smiles>

IV

Figure 22. Different ligation of 2,6-pydinedicaroxylates.

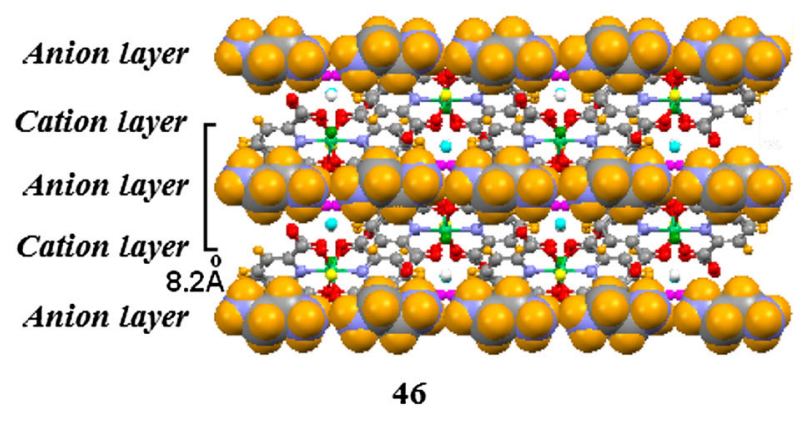

(a)

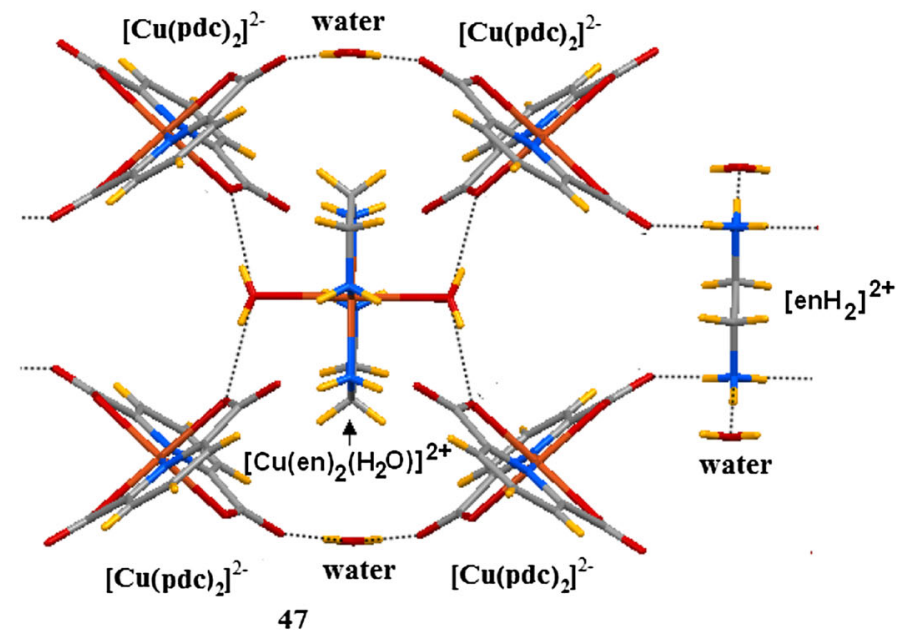

(b)

Figure 23. (a) Layer-like packing in $\left[\mathrm{H}_{2} e n\right]\left[\mathrm{Ni}(p d c)_{2}\right] \cdot 2 \mathrm{H}_{2} \mathrm{O}$; (b) Packing pattern of $\left[\mathrm{H}_{2} e n\right]\left[\mathrm{Cu}(e n)_{2}\left(\mathrm{H}_{2} \mathrm{O}\right)_{2}\right]$. $\left[\mathrm{Cu}(p d c)_{2}\right]_{2} \cdot \mathrm{H}_{2} \mathrm{O}$.

and completes the cyclic motif for encapsulation. The encapsulated units are hydrogen bonded to free ethylenediammonium dications illustrated in Figure 23b. The copper complex has channels comprising of anions and water molecules where cations are held (Figure 23b). The distance between copper atoms of two adjacent anions is $\sim 9.44 \AA$. This larger distance between the layers is due to the presence of the relatively large inorganic cation $\left[\mathrm{Cu}(\mathrm{en})_{2}\left(\mathrm{H}_{2} \mathrm{O}\right)_{2}\right]^{2+}$.

\subsection{Solvents and substituents influencing self-assemblies}

Water clusters present in fluorescent complexes show much different emission features from their unsolvated complexes. For example, solid state luminescent properties of complexes $\left\{\left[\mathrm{Zn}(p h e n)(d c a)_{2}\right] \cdot 3 \mathrm{H}_{2} \mathrm{O} \cdot \mathrm{EtOH}\right\}_{n}$ and $\left\{\left[\mathrm{Zn}(22 b p y)(a b a)_{2}\right]\right.$. $\left.4 \mathrm{H}_{2} \mathrm{O}\right\}_{n}$ (phen $=1,10$-phenanthroline, $d c a=4$-dimethylam inocinnamate, $22 b p y=2,2$-bipyridine, $a b a=4$-dimethyl aminobenzoate), each has different water clusters in their respective self-assembly. They show red shifts in the respective emission spectra with respect to the emission spectra of the corresponding unsolvated complex. ${ }^{25,129}$ Reversible loss of solvent of crystallisation and solvation were observed in these complexes.

Nickel(II) bis-2,6-pyridinedicarboxylate possessing monoprotonated 4-aminobenzyl ammonium cation, stabilizes hexameric water clusters. The water clusters are held in channel-like structures (Figure 24a). ${ }^{130}$ On the other hand, $\left[\mathrm{Co}(\text { phen })_{2}\left(\mathrm{H}_{2} \mathrm{O}\right)_{2}\right]\left[\mathrm{Zn}(p d c)_{2}\right] \cdot 7 \mathrm{H}_{2} \mathrm{O}$ possesses centrosymmetric cyclic decameric water clusters (Figure 24b). Such cyclic decamer propagates as infinite two-dimensional chain. Discrete decameric water units are commonly observed ${ }^{16}$ but the aggregation of decameric water clusters forming infinite $2 \mathrm{D}$ decameric cluster is unusual.

Wide variations in self-assemblies are brought about by varying the amount of coordinated water and charge on the cationic part of a supramolecular anionic templates. ${ }^{131,132}$ 


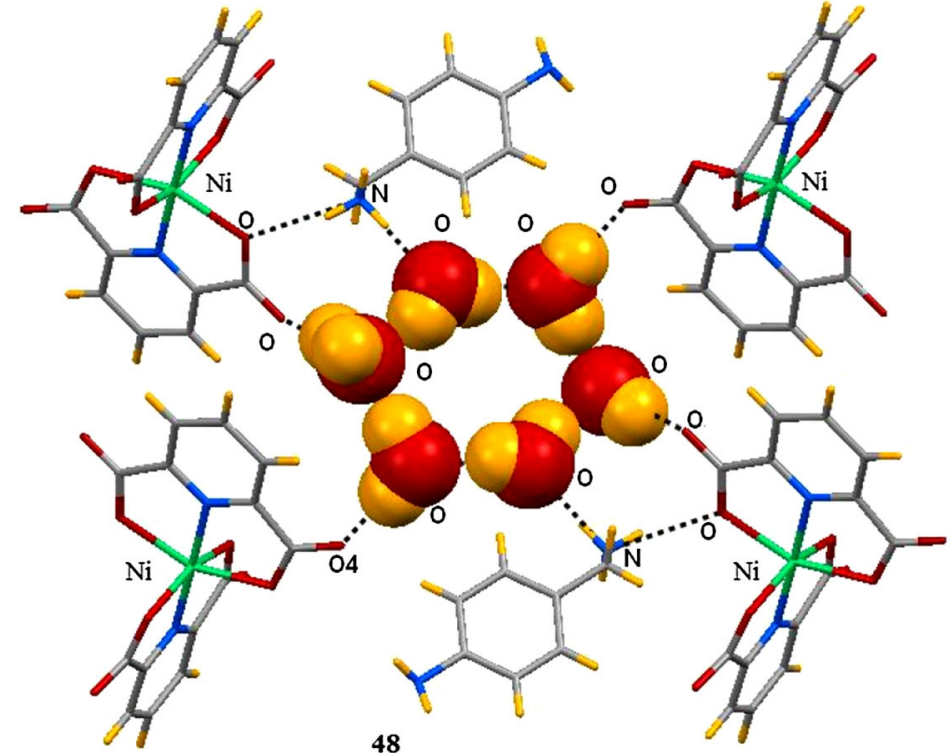

(a)

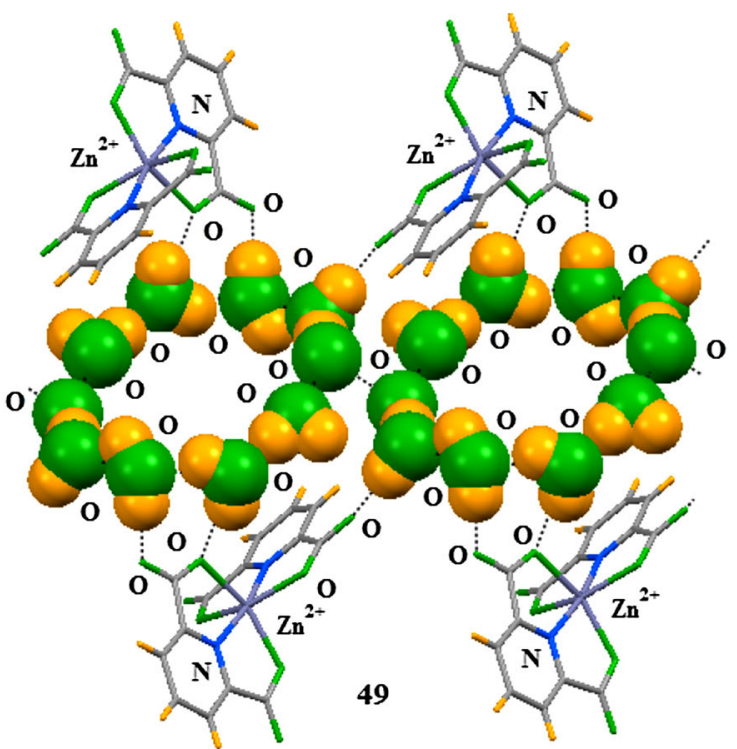

(b)

Figure 24. (a) Anions embedding a hexameric water cluster (space filled mode) in nickel-2,6-pyridinedicarboxylate complex possessing 4-aminobenzyl ammonium cation. (b) A decameric water cluster embedded by the anions of the $\left[\mathrm{Co}(\text { phen })_{2}\left(\mathrm{H}_{2} \mathrm{O}\right)_{2}\right]\left[\mathrm{Zn}(p d c)_{2}\right] \cdot 7 \mathrm{H}_{2} \mathrm{O}$ complex (cations are omitted).

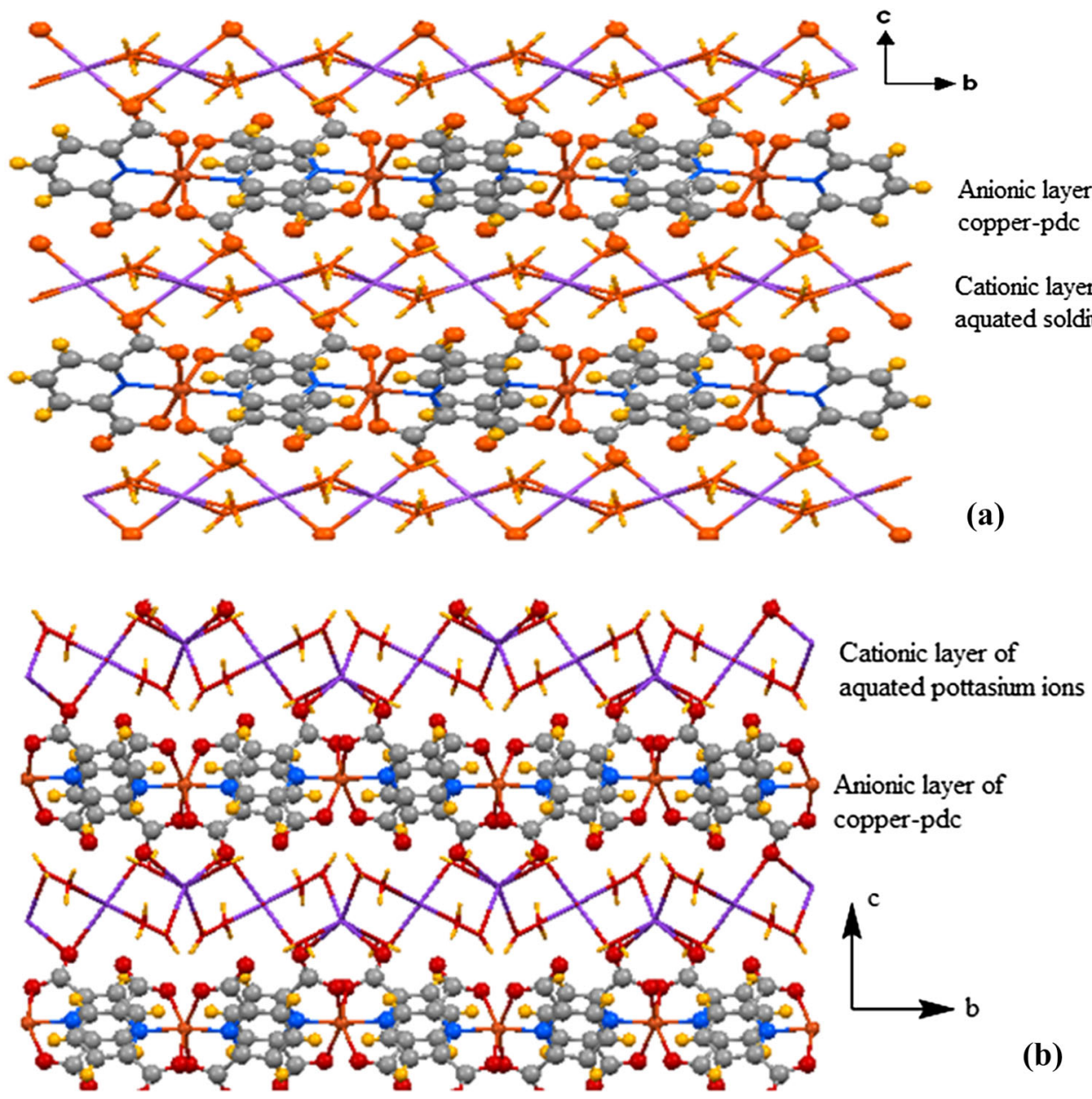

Figure 25. Layer-like structures found in (a) $\left\{\left[\mathrm{Na}\left(\mathrm{H}_{2} \mathrm{O}\right)_{2}\right]_{2}\left[\mathrm{Cu}(p d c)_{2}\right] \cdot 2 \mathrm{H}_{2} \mathrm{O}\right\}_{\mathrm{n}}$ and (b) $\left\{\left[\mathrm{K}_{2}\left(\mathrm{H}_{2} \mathrm{O}\right)_{7}\right]\left[\mathrm{Cu}(p d c)_{2}\right]\right\}_{\mathrm{n}}$. 


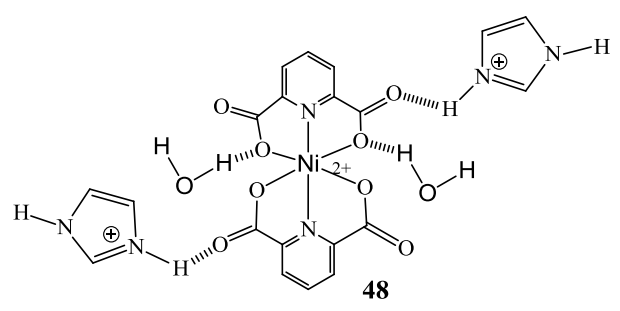

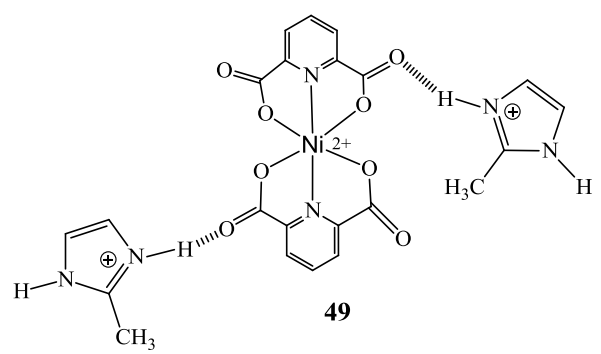

(a)

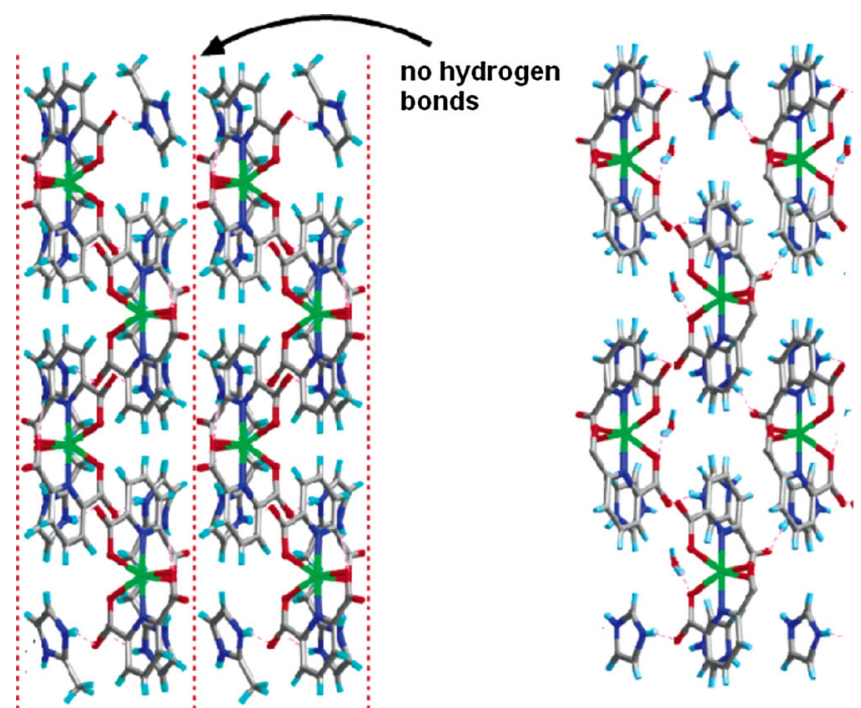

(b)

Figure 26. (a) Bis-imidazolium/2-methylimidazolium nickel(II) 2,6-pyridinedicarboxylate complexes; (b) Layer-like structures (crystallographic yz-plane) of $\left[(2 \text {-methylimidazolium })_{2}\right]\left[\mathrm{Ni}(p d c)_{2}\right]$ and [(imidazolium $\left.)_{2}\right]\left[\mathrm{Ni}(p d c)_{2}\right]$.

Compositions of copper 2,6-pyridinedicarboxylate complexes possessing sodium, potassium, magnesium, calcium ions are different; respective compositions are $\left\{\left[\mathrm{Na}\left(\mathrm{H}_{2} \mathrm{O}\right)_{2}\right]_{2}\right.$ $\left.\left[\mathrm{Cu}(p d c)_{2}\right] \cdot 2 \mathrm{H}_{2} \mathrm{O}\right\}_{\mathrm{n}},\left\{\left[\mathrm{K}_{2}\left(\mathrm{H}_{2} \mathrm{O}\right)_{7}\right]\left[\mathrm{Cu}(p d c)_{2}\right]\right\}_{\mathrm{n}}$ and $\left\{\mathrm{Ca}\left(\mathrm{H}_{2}\right.\right.$ $\left.\left.\mathrm{O})_{4}\right]\left[\mathrm{Cu}(p d c)_{2}\right] \cdot 2 \mathrm{H}_{2} \mathrm{O}\right\}_{\mathrm{n}},\left[\mathrm{Mg}\left(\mathrm{H}_{2} \mathrm{O}\right)_{5}\right]\left[\mathrm{Cu}(p d c)_{2}\right] \cdot 2 \mathrm{H}_{2} \mathrm{O}$. In these complexes copper- $p d c$ anions act as ligand/s to alkali or alkaline earth metal ion. Such complexes undergo cation exchanges easily. A few such complexes show semiconductor-like properties. ${ }^{132}$ Striking difference in sodium and potassium complex arises from aquation and coordination of water molecules. Self-assembly of $\{[\mathrm{Na}$ $\left.\left.\left(\mathrm{H}_{2} \mathrm{O}\right)_{2}\right]_{2}\left[\mathrm{Cu}(p d c)_{2}\right] \cdot 2 \mathrm{H}_{2} \mathrm{O}\right\}_{n}$ has di-aqua bridged sodium ions forming chain-like structures. Each sodium ion is associated to four-bridging aqua-ligands and two carboxylate oxygen atoms of $\left[\mathrm{Cu}(p d c)_{2}\right]^{2-}$. On the other hand, potassium ions also form non-covalent polymeric networks of $\left[\mathrm{K}_{2}\left(\mathrm{H}_{2} \mathrm{O}\right)_{7}\right]\left[\mathrm{Cu}(p d c)_{2}\right]$, where the $\mathrm{K}^{+}$ions are linked through three bridged aqua ligands and two terminal aqua ligands to make a hepta-coordinated geometry. These differences arise from the difference in size of the cations which changes the angle of alkali metal ions M-O-M bridges. Stacking among the rings of $p d c$ is observed with a distance $3.58 \AA$ between parallel rings (Figure 25). Due to strong electrostatic interactions between alkali metal ions and anions, the interlayer separations in the two complexes are similar.

Solvent-guided self-assemblies of platinum(II) phenylbipy ridine-bis(phenylisoxazolyl) phenylacetylide adopts a helical structure in toluene and it shows aggregation-induced enhancement of emission and aggregation-induced circularly polarized luminescence, whereas such optical properties are not observed in the solution of the complex in chloroform where it forms non-helical self-assembly. ${ }^{133}$

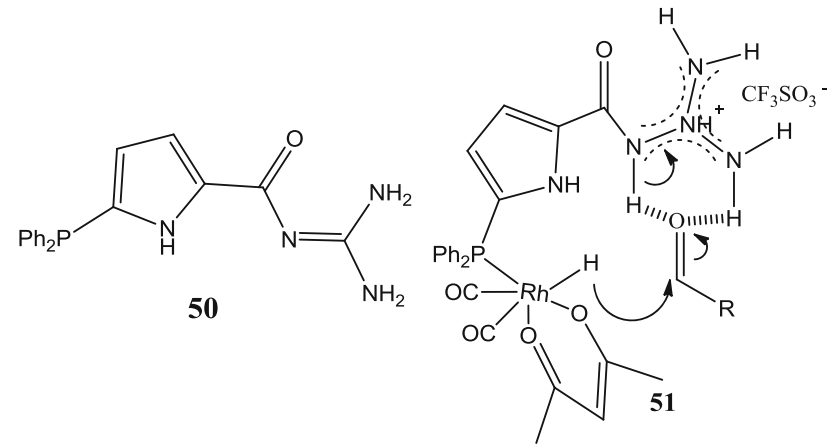

Figure 27. A phosphine ligand connected to guadinium (50) and an intermediate formed by self-assembly activating substrate (51).

The substituent on the cation makes a large difference in packing patterns of inorganic assemblies. One such example is bis-imidazolium/2-methylimidazolium nickel-pdc complexes. ${ }^{134}$ The packing patterns of two complexes are different, as shown in Figure 26b. Due to the difference the complex with the methyl substituent the packing pattern of the complex 49 adopts layer-like structure with repeat layers composed of two layers hydrogen bonded to each other layers whereas substitute case the repeat layers are monolayers each layer is connected to next layer by hydrogen bonds of intervening water molecules.

\subsection{Supramolecular inorganic assemblies in catalysis}

There are large numbers of examples where the catalytic effects of metal complexes are tuned by supramolecular interactions at remote sites from the coordination sphere and a few 


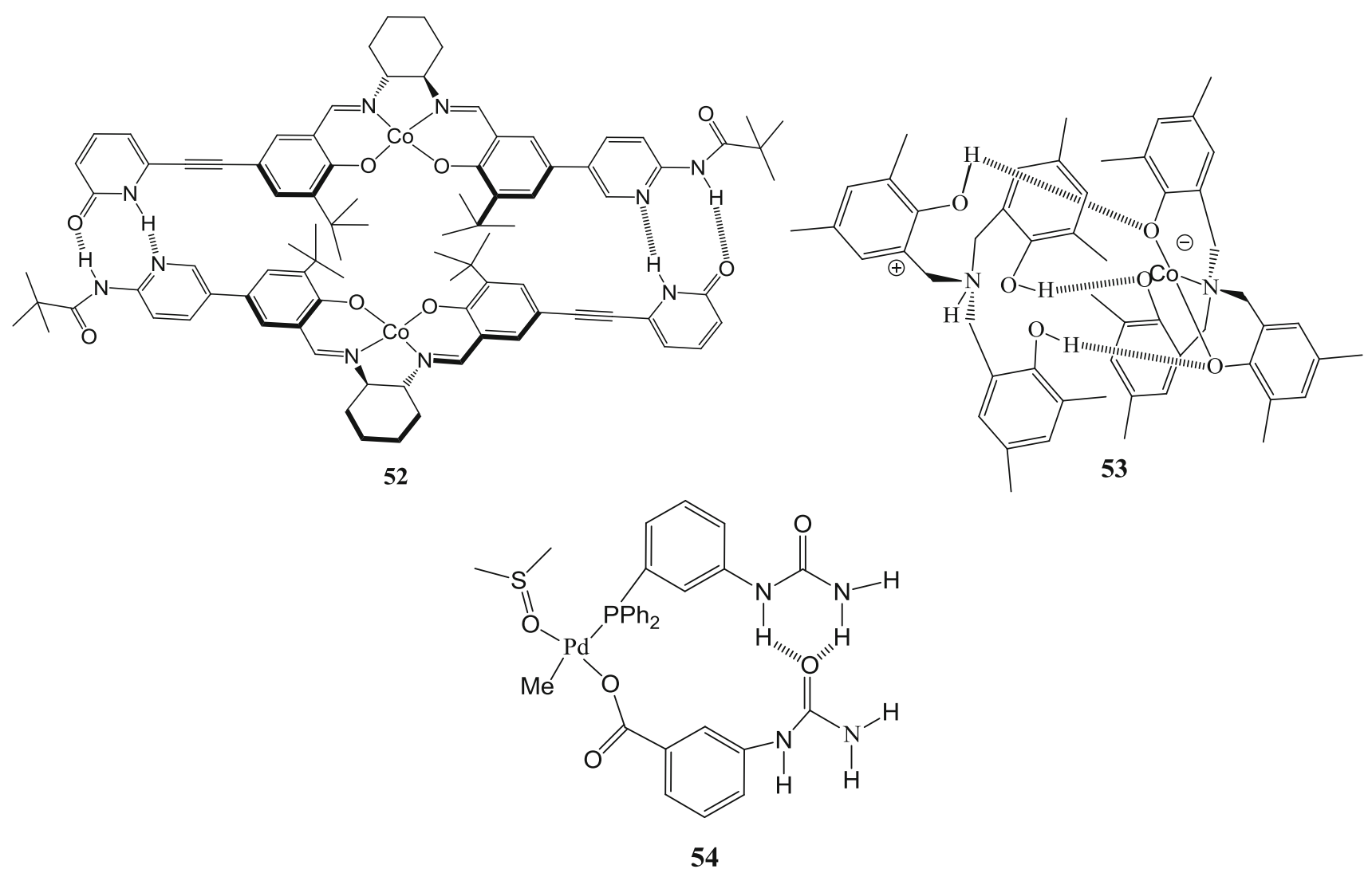

Figure 28. Supramolecular complexes with interesting reactivity.

of these complexes are designed as enzyme mimics. ${ }^{135}$ There are examples of organometallic catalyst where supramolecular features of the ligands help to increase the rate of a reaction and in selective product formation. Catalytic activity of the $\left[\mathrm{Rh}(\mathrm{CO})_{2}(a c a c)\right]$ (where $a c a c=$ acetylacetonate) catalyst enhances in presence of phosphine ligands tethered to guanidinium functionality. ${ }^{136}$ The ligand shown in Figure 27 forms complex with rhodium through phosphorus and the guadinium part forms hydrogen bonds with the carbonyl group of aldehyde. Such intermediate species facilitate the hydrogenation reaction of the carbonyl group.

Self-assembly through complementary hydrogen bonds between pyridone and pyridineamide units attached to chiral cobalt(II)-salen complex $\mathbf{5 2}$ (Figure 28) is a good catalyst for nitro-aldol condensation reactions. ${ }^{137}$ The self-assembly of monomer of similar cobalt(II)-salen complex, though a catalyst, the enantio-selectivity observed in hydrogen bonded dimeric catalyst is upto $97 \%$. The reaction follows second order kinetics in catalyst concentration.

Cobalt(II) complex of aminotrisphenolate ligands 53 possessing two different hemispheres of ligand and cation environment has been reported. ${ }^{138}$ In this complex, one hemisphere formed by cations and other by the complex anion are held together by hydrogen bonds, which are of interest as the metal cation gets embedded in capsule-like structure. This complex is easily oxidised to corresponding cobalt(III) complex and the hydrogen bonded cationic part gets dislodged. Accordingly, reaction with ligands such as dimethylaminopyridine and 2,2'-bipyridine, replaces the hydrogen bonded cationic part and cobalt(III) complexes are formed by incorporating the reacting ligands as additional counterpart along with tripodal aminotrisphenolate ligand.

Hydrogen-bonded urea taps incorporated to palladium complex ${ }^{139} \mathbf{5 4}$ is an efficient catalyst for olefin polymerisation. In such catalytic reactions, advantages of the supramolecular features of aryl urea are utilised. The aryl urea has $\mathrm{N}-\mathrm{H}$ protons which are less suitable for hydrogen bond than unsubstituted urea and the aryl-group provides steric as well as hydrophobic effect. These effects contribute to enhanced catalytic activity of the palladium complex over the one lacking the urea part in polymerisation reaction of ethylene.

\section{Outlook and conclusions}

Above discussions suggest self-assemblies guided by ligands of inorganic complexes and their host-guest complexes provide molecular understanding reflecting on the material properties, and to generate assembled structures of simple inorganic ionic complexes with interesting properties. ${ }^{140-142}$ Study on these assemblies at the interfaces provides interesting optical, magnetic, electrical and transport properties and provides a basis for the epitaxial growth of crystals with modified properties with respect to a parent crystal. The strength of 
associations with guests and kinetics of delivery caters to understand transport and delivery of guests. Identification of stable host-assemblies from which guest can be easily removed, ${ }^{143-148}$ search for new templates for molecular recognitions, ${ }^{149-153}$ self-assembling leading to properties such as gelation, ${ }^{154}$ will continue to be challenges. Host-guest assemblies with comparable sizes and their recognition of, for example, $\mathrm{C}_{60}$ as guest included in metal-porphyrin ${ }^{155,156}$ for photochemical conversion have future ahead. Furthermore, stimulusguided changes in assemblies will continue to make impacts in processes like resonance energy transfer and other aggregation induced photoluminescence properties. Thus, this rapidly growing topic on self-assemblies of inorganic complexes requires systematic attention and concerted effort on the design and energetics in order to have control on the synthesis and properties.

\section{References}

1. Cademartiri L and Bishop K J M 2015 Programmable self-assembly Nat. Mater. 142

2. Desiraju G R, Vittal J J and Ramanan A 2011 Crystal Engineering (Singapore: World Scientific)

3. Simard M, Su D and Wuest J D 1991 Use of hydrogen bonds to control molecular aggregation. Self-assembly of three-dimensional networks with large chambers $J$. Am. Chem. Soc. 1134696

4. Ermer O 1988 Five-fold diamond structure of adamantane-1,3,5,7-tetracarboxylic acid J. Am. Chem. Soc. 1103747

5. Peraka K S, Lusi M, Bajpai A and Zaworotko M J 2017 Crystal engineering approach to generate crystalline inclusion compounds in which 5-hydroxyisophthalic acid serves as a host Cryst. Growth Des. 17959

6. MacNicol D D 1984 Inclusion Compounds (London: Academic Press) Vol. 2, pp. 1-45

7. Burchell T J, Eisler D J and Puddephatt R J 2006 Hierarchy of hydrogen bonding versus anion binding in self-assembled network structures of silverI Cryst. Growth Des. 6974

8. Kobr L, Zhao K, Shen Y, Comotti A, Bracco S, Shoemaker R K, Sozzani P, Clark N A, Price J C, Rogers C T and Michl J 2012 Inclusion compound based approach to arrays of artificial dipolar molecular rotors. A surface inclusion J. Am. Chem. Soc. 13410122

9. Zhou H C, Long J R and Yaghi O M 2012 Introduction to metal-organic frameworks Chem. Rev. 112673

10. Zhou H C and Kitagawa S 2014 Metal-organic frameworks MOFs Chem. Soc. Rev. 435415

11. Soares C V, Borges D D, Wiersum A, Martineau C, Nouar F, Llewellyn P L, Ramsahye N A, Serre C, Maurin G and Leitao A A 2016 Adsorption of small molecules in the porous zirconium-based metal organic Framework MIL-140A Zr.: A joint computationalexperimental approach J. Phys. Chem. C $\mathbf{1 2 0} 7192$
12. Zhang $\mathrm{L}, \mathrm{Wu} \mathrm{G}$ and Jiang $\mathrm{J} 2014$ Adsorption and diffusion of $\mathrm{CO}_{2}$ and $\mathrm{CH}_{4}$ in zeolitic imidazolate framework-8: effect of structural flexibility J. Phys. Chem. C 1188788

13. Thallapally P K, McGrail B P, Dalgarno S J, Scafe H T, Tian J and Atwood J L 2008 A partially interpenetrated metal-organic framework for selective hysteretic sorption of carbon dioxide Nat. Mater. 7 146

14. Iritani K, Tahara K, De Feyter S and Tobe Y 2017 Hostguest chemistry in integrated porous space formed by molecular self-assembly at liquid-solid interfaces Langmuir 334601

15. Barbour L J, Orr G W and Atwood J L 1998 An intermolecular $\mathrm{H}_{2} \mathrm{O}$. 10 cluster in a solid-state supramolecular complex Nature 393671

16. Das S and Bharadwaj P K 2006 Water clusters gather luminescent zinc(II) complexes around hydrogenbonded framework structures and associated fluorescence modulation Cryst. Growth Des. 6187

17. Fernandes R R, Kirillov A M, Fatima M, da Silva C G, Ma Z, da Silva J A L, da Silva J J R F and Pombeiro A J L 2008 An infinite two-dimensional hybrid water-chloride network, self-assembled in a hydrophobic terpyridine iron(II) matrix Cryst. Growth Des. 8 782

18. Wu L -M, Teng $\mathrm{H}-\mathrm{B}$, Feng $\mathrm{X}-\mathrm{C}$, Ke $\mathrm{X}$ B, Zhu Q -F, Su J -T, Xu W -J and $\mathrm{Hu}$ X -M 2007 Supramolecular networks in crystals of metal(II) complexes with water-soluble salicylaldehyde-2-sulfobenzoylhydrazone anion ligand Cryst. Growth Des. 71337

19. Chakraborty B and Paine T K 2011 Synthesis and characterization of cobalt(II)-salicylate complexes derived from $\mathrm{N}_{4}$-donor ligands: stabilization of a hexameric water cluster in the lattice host of a cobaltI(II)-salicylate complex. Inorg. Chim. Acta $\mathbf{3 7 8} 231$

20. Prasad T K and Rajasekaran M V 2006 A novel water octamer in [Cedipic ${ }_{2} \mathrm{H}_{2} \mathrm{O}_{3}$ ] $\cdot 4 \mathrm{H}_{2} \mathrm{O}$ : Crystallographic, thermal, and theoretical studies Cryst. Growth Des. 6 488

21. Das M C, Maity S B and Bharadwaj P K 2009 Supramolecular association of water molecules forming discrete clusters in the voids of coordination polymers Curr. Opin. Solid State Mater. Sci. 1376

22. Colak T A, Yesilel O Z and Buyukgungor O 2001 Synthesis, structural characterisation of zinc(II)-pyridine2,5-dicarboxylate complexes and self-assembled 1D water cluster in a supramolecular architecture Polyhedron 292127

23. Pluth M D and Raymond K N 2007 Reversible guest exchange mechanisms in supramolecular host-guest assemblies Chem. Chem. Soc. Rev. 36161

24. Singh D and Baruah J B 2012 Solid state assemblies of cyclic imides tethered hydroxybenzoic acids with pyridine and quinoline: Toward the formation of channels and cavities Cryst. Growth Des. 123169

25. Davis A V, Yeh R M and Raymond K N 2002 Supramolecular assembly dynamics Proc. Nat. Acad. Sci. USA 994793

26. Frechet J M J 2002 Dendrimers and supramolecular chemistry Proc. Nat. Acad. Sci. USA 994782 
27. Tarai A and Baruah J B 2016 Anion assisted conformationally guided self-assemblies of multicomponent cocrystals of dioxime CrystEngComm 18 5482

28. McNaught A D and Wilkinson A 1997 Compendium of chemical terminology; IUPAC recommendations

29. Nassimbeni L R 2003 Physicochemical aspects of hostguest compounds Acc. Chem. Res. 36631

30. Cram D J and Cram J M 1997 In Container molecules and their guests (London: Royal Society of Chemistry)

31. Vogtle F 1991 In Supramolecular Chemistry (Chichester: Wiley)

32. Machadoa V G, Baxter P N W and Lehn J -M 2001 Selfassembly in self-organized inorganic systems: A view of programmed metallosupramolecular architectures $J$. Braz. Chem. Soc. 12431

33. Stang P J and Olenyuk B 1997 Self-assembly, symmetry, and molecular architecture: Coordination as the motif in the rational design of supramolecular metallacyclic polygons and polyhedra Acc. Chem. Res. 30 502

34. Hoeben F J M, Jonkheijm P, Meijer E W and Schenning A P H J 2005 About supramolecular assemblies of $\pi$ conjugated systems Chem. Rev. 1051491

35. Lehn J -M 2002 Toward complex matter: Supramolecular chemistry and self-organization Proc. Nat. Acad. Sci. USA 994763

36. Whitesides G M and Boncheva M 2002 Beyond molecules: Self-assembly of mesoscopic and macroscopic components Proc. Nat. Acad. Sci. USA 994769

37. Lv J, Liu H and Li Y 2008 Self-assembly and properties of low-dimensional nanomaterials based on $\pi$ conjugated organic molecules Pure. Appl. Chem. 80 639

38. Whitesides G M, Mathias J P and Seto C T 1991 Molecular self-assembly and nanochemistry: a chemical strategy for the synthesis of nanostructures Science 2541312

39. Adachi T and Ward M D 2016 Versatile and resilient hydrogen-bonded host frameworks. Acc. Chem. Res. 49 2669

40. Tiekink E R T 2017 Supramolecular assembly based on "emerging" intermolecular interactions of particular interest to coordination chemists Coord. Chem. Rev. 345 209

41. Titi H M, Tripuramallu B K and Goldberg I 2016 Porphyrin-based assemblies directed by non-covalent interactions: highlights of recent investigations CrystEngComm 183318

42. Davis J T and Spada G P 2007 Supramolecular architectures generated by self-assembly of guanosine derivatives Chem. Soc. Rev. 36296

43. Blake A J, Champness N R, Hubberstey P, Li W -S, Withersby M A and Schroder M 1999 Inorganic crystal engineering using self-assembly of tailored buildingblocks Coord. Chem. Rev. 183117

44. Das N, Ghosh A, Arif A M and Stang P J 2005 Self-assembly of neutral platinum-based supramolecular ensembles incorporating oxocarbon dianions and oxalate Inorg. Chem. 447130

45. Friscic T, Mestrovic E, Samec S, Kaitner B and Fabian L 2009 One-pot mechanosynthesis with three levels of molecular self-assembly: Coordination bonds, hydrogen bonds and host-guest inclusion Chem. Eur. J. 1512644

46. Beatty A M 2003 Open-framework coordination complexes from hydrogen-bonded networks: toward host/guest complexes. Coord. Chem. Rev. 246131

47. Beatty A M and Helfrich B A, Hogan G A and Reed B A 2006 Metal-containing dicarboxylic acids as building blocks for lamellar inorganic-organic Hybrid Networks Cryst. Growth Des. 6122

48. Hartshorn C M and Steel P J 1996 Self-Assembly and $\mathrm{X}$-ray structure of a dimetalloparacyclophane incorporating a $\pi-\pi$ stacked subunit Inorg. Chem. 35 6902

49. Litvinov A L, Konarev D V, Kovalevsky A Y, Neretin I S, Coppens P and Lyubovskaya R N 2005 Fullerene complexes with supramolecular zinc tetraphenylporphyrin assemblies: synthesis, crystal Structures, and optical properties Cryst. Growth Des. 51807

50. Barooah N, Sarma R J and Baruah J B 2006 Metal directed assemblies of a dipeptide: Formation of $\beta$ pleated sheets Eur. J. Inorg. Chem. 152942

51. $\mathrm{Xu} F-\mathrm{F}$, Li $\mathrm{Q}-\mathrm{S}$, Zeng $\mathrm{X}-\mathrm{S}$, Leng $\mathrm{X}-\mathrm{B}$ and Zhang Z -Z 2004 Bimetallocyclophanes formed by the $\pi-\pi$ stacking interaction approach and fluorescent chemosensing behavior Organometallics 23632

52. Fu H L, Po C, Leung S Y and Yam V W 2017 Self-assembled architectures of alkynylplatinum(II) amphiphiles and their structural optimization: A balance of the interplay among $\mathrm{Pt} \cdots \mathrm{Pt}, \pi-\pi$ stacking, and hydrophobic-hydrophobic interactions ACS Appl. Mater. Interfaces $\mathbf{9} 2786$

53. Nath B and Baruah J B 2012 Metallacycles of cadmium, mercury dicarboxylates Dalton Trans. 417115

54. Adarsh N N, Chakraborty A, Tarres M, Dey S, Novio F, Chattopadhyay B, Ribas X and Ruiz-Molina D 2017 Ligand and solvent effects in the formation and self-assembly of a metallosupramolecular cage New J. Chem. 411179

55. Pirondini L, Bertolini F, Cantadori B, Ugozzoli F, Massera C and Dalcanale E 2002 Design and selfassembly of wide and robust coordination cages Proc. Nat. Acad. Sci. USA 994911

56. Bania K, Barooah N and Baruah J B 2007 Structural variations in self-assembled cadmium benzoate complexes Polyhedron 262612

57. Karmakar A, Sarma R J and Baruah J B 2006 Self-assembly of neutral dinuclear and trinuclear zinc-benzoate complexes Inorg. Chem. Commun. 9 1169

58. Singh D and Baruah J B 2012 Metal (II) complexes derived from conformation flexible cyclic imides tethered carboxylic acids: syntheses, supramolecular structures, and molecular properties Cryst. Growth Des. 12 2109

59. Sanchez-Serratos M, Alvarez J R, Gonzalez-Zamora E and Ibarra I A 2016 Porous coordination polymers PCPs.: new platforms for gas storage Mex. Chem. Soc. 6043

60. Marinescu G, Ferlay S, Kyritsakas N and Hosseini M W 2013 Molecular tectonics: from crystals to crystals of crystals Chem. Commun. 4911209 
61. Nishio M, Umezawa Y, Fantini J, Weiss M S and Chakrabarti $\mathrm{P} 2014 \mathrm{CH}-\pi$ hydrogen bonds in biological macromolecules Phys. Chem. Chem. Phys. 1612648

62. Takahashi O, Kohno Y and Nishio M 2010 Relevance of weak hydrogen bonds in the conformation of organic compounds and bioconjugates: evidence from recent experimental data and high-level ab Initio MO calculations Chem. Rev. 1106049

63. Hunter C A and Sanders J K M 1990 The nature of $\pi-\pi$ interactions J. Am. Chem. Soc. 1125525

64. Cozzi F, Cinquini M, Annuziata R and Siegel J S 1993 Dominance of polar/a over charge-transfer effects in stacked phenyl interactions. J. Am. Chem. Soc. 1155330

65. Adams H, Hunter C A, Lawson K R, Perkins J, Spey S E, Urch C J and Sanderson J M 2001 A supramolecular system for quantifying aromatic stacking interactions Chem. Eur. J. 74863

66. Henkel S, Misuraca M C, Ding Y, Guitet M and Hunter CA 2017 Enhanced chelate cooperativity in polar solvents J. Am. Chem. Soc. 1396675

67. Tadokoro M, Kanno H, Kitajima T, Shimada-Umemoto H, Nakanishi N, Isobe K and Nakasuji K 2002 Selforganizing super-structures formed from hydrogenbonded biimidazolate metal complexes Proc. Nat. Acad. Sci. USA 994950

68. Murata T, Yakiyama Y, Nakasuji K and Morita Y 2010 Supramolecular architectures and hydrogen-bond directionalities of $4,4^{\prime}$-biimidazole metal complexes depending on coordination geometries Cryst. Growth Des. 104898

69. Atencio R, Chacon M, Gonzalez T, Briceno A, Agrifoglio $G$ and Sierraalt A 2004 Robust hydrogen-bonded self-assemblies from biimidazole complexes. Synthesis and structural characterization of [Mbiimidazole $\cdot 2$ $\left.\mathrm{OH}_{2} \cdot 2\right]^{2+}\left(\mathrm{M}=\mathrm{Co}^{2+}, \mathrm{Ni}^{2+}\right)$ complexes and carboxylate modules Dalton Trans. 4505

70. Tadokoro M and Nakasuji K 2000 Hydrogen bonded 2, 2'-biimidazolate transition metal complexes as a tool of crystal engineering. Coord. Chem. Rev. 198205

71. Sang $\mathrm{R}-\mathrm{L}$ and $\mathrm{Xu}$ L 2006 Counteranion-induced formation of cis and trans singly and doubly $\mathrm{H}_{2}$ biimbridged di-, hexa-, and polymeric $\mathrm{Ag}-\mathrm{H}_{2}$ biim complexes Eur. J. Inorg. Chem. 61260

72. Indumathy R, Weyhermuller T and Nair B U 2010 Biimidazole containing cobaltI(II) mixed ligand complexes: Crystal structure and photonuclease activity Dalton Trans. 392087

73. Hosseini M W 2003 Molecular tectonics: From molecular recognition of anions to molecular networks. Coord. Chem. Rev. 240157

74. Lewis G R and Orpen A G 1998 A metal-containing synthon for crystal engineering: synthesis of the hydrogen bond ribbon polymer $\left[4,4^{\prime}-\mathrm{H}_{2}\right.$ bipy $]\left[\mathrm{MCl}_{4}\right](\mathrm{M}=$ Pd, Pt)Chem. Commun. 171873

75. Mareque-Rivas J C and Brammer L 1998 Self-assembly of 1-D chains of different topologies using the hydrogen-bonded inorganic supramolecular synthons $\mathrm{N}-\mathrm{H}$ ...Cl_2M or N-H ...Cl_3M Inorg. Chem. 374756

76. Gillon A L, Orpen A G, Starbuck J, Wang X -M, Rodriguez-Martin Y and Ruiz-Perez C 1999 Cationcontrolled formation of $\left[\left\{\mathrm{MCl}_{4}\right\}_{n}\right]^{2 \mathrm{n}-}$ chains in $\left[4,4^{\prime}-\right.$ $\mathrm{H}_{2}$ bipy $]\left[\mathrm{MCl}_{4}\right](\mathrm{M}=\mathrm{Mn}, \mathrm{Cd})$ : an alternative to the $\mathrm{A}_{2} \mathrm{MCl}_{4}$ [100] layer perovskite structure Chem. Commun. 222287

77. Dolling B, Gillon A L, Orpen A G, Starbuck J and Wang X-M 2001 Homologous families of chloride-rich 4, 4'-bipyridinium salt structures Chem. Commun. 6 567

78. Angeloni A and Orpen A G 2001 Control of hydrogen bond network dimensionality in tetrachloroplatinate salt Chem. Commun. 4343

79. Braga D, Maini L, Polito M, Tagliavini E and Grepioni F 2003 Design of hydrogen bonded networks based on organometallic sandwich compounds Coord. Chem. Rev. 24653

80. Bassanetti I, Comotti A, Sozzani P, Bracco S, Calestani G, Mezzadri F and Marchioo L 2014 Porous molecular crystals by macrocyclic coordination supramolecules $J$. Am. Chem. Soc. 13614883

81. Papaefstathiou G S, Keuleers R, Milios C J, Raptopoulou C P, Terzis A, Desseyn H O and Perlepes S P 2003 Metal complexes of biologically important ligands, synthesis of peptides from glycine ester catalysed by triflates and chlorides of metal (III, IV, V and VI) ions Z. Naturforsch. 58b 74

82. Carballo R, Covelo B, Lodeiro C and Vazquez-Lopez E M 2005 One-dimensional fluorescent stacking structure based on zinc mixed-complex salt encapsulated within an 'ice-like' three-dimensional hydrogen-bonded water network CrystEngComm 7294

83. Kawade V A, Kumbhar A S, Erxleben A, Pachfulec P and Banerjee R 2011 Hydrogen bond directed honeycomb-like porous network structure of trisbipyridyl-glycoluril.cobaltI(II) chloride CrystEngComm 135289

84. Dalrymple S A and Shimizu G K H 2007 Crystal engineering of a permanently porous network sustained exclusively by charge-assisted hydrogen bonds $\mathrm{J}$. Am. Chem. Soc. 12912114

85. Friscic T, Mestrovic E, Samec D S, Kaitner B and Fabian L 2009 One-pot mechanosynthesis with three levels of molecular self-assembly: coordination bonds, hydrogen bonds and host-guest inclusion Chem. Eur. J. 1512644

86. Karmakar A, Sarma R J and Baruah J B 2007 Polymorphism in an aqua-bridged, dinuclear 2-nitrobenzoate complex of cobalt(II) Eur. J. Inorg. Chem. 5643

87. Choudhury S R, Dey B, Das S, Robertazzi A, Jana A D, Chen C -Y, Lee H M, Gamez P and Mukhopadhyay S 2009 Robust recognition of malonate and 2-amino4-picolinium in conjunction with $\mathrm{M}(\mathrm{II})$ as a triad $\mathrm{M}=$ $\mathrm{Ni} / \mathrm{Co} / \mathrm{Mn} .:$ Role of this highly stable hydrogen-bonded motif in driving supramolecular self-assembly Dalton Trans. 377617

88. Das A, Dey B, Jana A D, Hemming J, Helliwell M, Lee H M, Hsiao T -H, Suresh E, Colacio E, Choudhury S R and Mukhopadhyay S 2010 Effect of protonated aminopyridines on the structural divergences of $\mathrm{M}(\mathrm{II})$ malonate complexes $(\mathrm{M}=\mathrm{Cu}, \mathrm{Ni}, \mathrm{Co})$ Polyhedron 29 1317

89. Das A, Choudhury S R, Estarellas C, Dey B, Choudhury A S R, Jana A D, Colacio E, Lee H M, Mostafa G and Mukhopadhyay S 2007 Crowned tetrameric spirocyclic water chain: An unusual building block of a 
supramolecular metal-organic host Cryst. Growth Des. 7212

90. Mitra M, Seth S K, Choudhury S R, Manna P, Das A, Helliwell M, Bauza A, Frontera A and Mukhopadhyay $\mathrm{S} 2013 \mathrm{M}^{\mathrm{II}}-$ Malonate complexes $(\mathrm{M}=\mathrm{Mg}, \mathrm{Cu}, \mathrm{Ni}$ and Co) characterized by layered structures: Experimental observation, Hirshfeld surface analysis and theoretical study Eur. J. Inorg. Chem. 264679

91. Burrows A D, Frost C G, Mahon M F, Raithby P R, Renouf C L, Richardson C and Stevenson A J 2010 Dipyridyl $\beta$-diketonate complexes: versatile polydentate metalloligands for metal-organic frameworks and hydrogen-bonded networks Chem. Commun. 465067

92. Bray D J, Clegg J K, Jolliffe K A and Lindoy L F 2014 Cobalt(II), iron(II), zinc(II) and palladium(II) complexes of di-topic 4'-\{4-[bis2-pyridyl-aminomethyl]phenyl $\}-2,2^{\prime}: 6^{\prime}, 2^{\prime \prime}$ terpyridine. Synthetic and X-ray structural studies CrystEngComm 166476

93. Shee N K, Naskar J P, Drew M G B, Aliaga-Alcalde $\mathrm{N}$ and Datta D 2015 Stabilisation of true $\pi$-electron$\pi$-electron interactions in an inorganic cocrystal Inorg. Chim. Acta 42797

94. Goldberg I 2000 Metallopophyrin molecular sieves Chem Eur. J. 63863

95. Abrahams B F, Hoskins B F, Michall D M and Robson R 1994 Assembly of porphyrin building blocks into network structures with large channels Nature 369727

96. Dastidar P, Stein Z, Goldberg I and Strouse C E 1996 Supramolecular assembly of functionalized metalloporphyrinssporous crystalline networks of zinc-tetra4carboxyphenyl.porphyrin Supramol. Chem. 7257

97. Byrn M P, Curtis C J, Hsiou Y, Khan S I, Sawin P A, Tendick S K, Terzis A and Strouse C E A 1993 Porphyrin sponges: conservative of host structure in over 200 porphyrin-based lattice clathrates J. Am. Chem. Soc. 1159480

98. Goldberg I 2002 Design strategies for supramolecular porphyrin-based materials-highlight CrystEngComm 4 109

99. Bhyrappa P, Wilson S R and Suslick K S 1997 Hydrogen bonded porphyrinic solids: supramolecular networks of octahydroxy porphyrins J. Am. Chem. Soc. 1198492

100. Singh S, Aggarwal A, Farley C, Hageman B A, Batteas J D and Drain C M 2011 Hierarchical organization of a robust porphyrin cage self-assembled by hydrogen bonds Chem. Commun. 477134

101. Suslick K S, Bhyrappa P, Chou J -H, Kosal M, Nakagaki S, Smithenry D W and Wilson S R 2005 Microporous Porphyrin Solids Acc. Chem. Res. 38283

102. Moreira L, Calbo J, Illescas B M, Arag J, Nierengarten I, Delavaux-Nicot B, Ort E, Martn N and Nierengarten J -F 2015 Metal-atom impact on the self-assembly of cupand-ball metalloporphyrin-fullerene conjugates Angew. Chem. Int. Edit. 541255

103. Konarev D V, Khasanov S S and Lyubovskaya R M 2014 Fullerene complexes with coordination assemblies of metalloporphyrins and metal phthalocyanines Coord. Chem. Rev. $\mathbf{2 6 2} 16$

104. Chandra B K C and D'Souza F 2016 Design and photochemical study of supramolecular donor-acceptor systems assembled via metal-ligand axial coordination Coord. Chem. Rev. 322104

105. Lebedeva M A, Chamberlain T W, Davies E S, Mancel D, Thomas B E, Suyetin M, Bichoutskaia E, Schreder M and Khlobystov A N 2013 Transition metal complexes of a salen-fullerene diad: redox and catalytically active nanostructures for delivery of metals in nanotubes Chem. Eur. J. 1911999

106. He L, Ma D, Duan L, Wei Y, Qiao J, Zhang D, Dong G, Wang L and Qiu Y 2012 control of intramolecular $\pi-\pi$ stacking interaction in cationic Iridium complexes via fluorination of pendant phenyl rings Inorg. Chem. 514502

107. Sivakova S and Rowan S J 2005 Nucleobases as supramolecular motifs Chem. Soc. Rev. 349

108. Hunter C A 1993 The role of base stacking interactions J. Mol. Biol. 2301025

109. Bhattacharyya D, Arachchilage G M and Basu S G and Basu S 2016 Metal cations in G-quadruplex folding and stability Front Chem. 438

110. Garah M E, Perone R C, Bonilla A S, Haar S, Campitiello M, Gutierrez R, Cuniberti G, Masiero S, Ciesielski A and Samorı P 2015 Guanosine-based hydrogen-bonded 2D scaffolds: metal-free formation of G-quartet and G-ribbon architectures at the solid/liquid interface Chem. Commun. 5111677

111. Zhang S, Wu Y and Zhang W 2014 G-Quadruplex structures and their interaction diversity with ligands ChemMedChem. 9899

112. Garcia-Teran J P, Castillo O, Luque A, Garcia-Couceiro U, Beobide G and Roman P 2006 Supramolecular architectures assembled by the interaction of purine nucleobases with metal-oxalato frameworks. Non-covalent stabilization of the $7 \mathrm{H}$-adenine tautomer in the solidstate Dalton Trans. 7902

113. Garcia-Teran J P, Castillo O, Luque A, Garcia-Couceiro U, Beobide G and Roman P 2007 Molecular recognition of adeninium cations on anionic metal-oxalato frameworks: An experimental and theoretical analysis Inorg. Chem. 463593

114. Marian C, Nolting D and Weinkauf R 2005 The electronic spectrum of protonated adenine: Theory and experiment Phys. Chem. Chem. Phys. 73306

115. Das B, Boudalis A K and Baruah J B 2010 Selective adenine/cytosine cations in one-dimensional coordination polymers of manganese(II) and copper(II) 2,3-pyridine dicarboxylates Inorg. Chem. Commun. 131244

116. Garcia-Teran J P, Castillo O, Luque A, Garcia-Couceiro U, Beobide G and Roman P 2007 Molecular recognition of protonated cytosine ribbons by metal-oxalato frameworks Cryst. Growth Des. 72594

117. Das B and Baruah J B 2010 Protonated adenine and cytosine ribbons stabilized by dipicolinato metal frameworks Cryst. Growth Des. 103242

118. Salam M A and Aoki K 2000 Interligand interactions affecting specific metal bonding to nucleic acid bases: the tripodal nitrilotriacetato (nta) ligand-system. Crystal structures of [(nta)(adeninium)(aqua)nickel(II)] hydrate, [(nta)(diaqua)nickel(II)].(cytosinium) hydrate, and $[($ nta)(diaqua)nickel(II)].(cytosinium).(cytosine) hydrate 
119. Das B and Baruah J B 2012 Assembling of copper (II) dipicolinate complexes Polyhedron 31361

120. Malenov D P, Janjic G V, Medakovic V B, Hall M B and Zaric S D 2017 Noncovalent bonding: Stacking interactions of chelate rings of transition metal complexes. Coord. Chem. Rev. 345318

121. Shankar K, Kirillov A M and Baruah J B 2015 A modular approach for molecular recognition by zinc dipicolinate complexes Dalton Trans. 4414411

122. Shankar K, Singh M P and Baruah J B 2018 Extent of protonation of $4,4^{\prime}$-bipyridinium cations and nature of host influences the amount of guest intake by cobalt(II) 2,6-pyridinedicarboxylate Inorg. Chim. Acta $\mathbf{4 6 9} 440$

123. Shankar K and Baruah J B 2017 Inclusion of dihydroxyaromatics by a lanthanumI(II) 2,6-dipicolinate complex Polyhedron 126262

124. Kirillova M V, da Silva M F C G, Kirillov A M, da Silva J J R F and Pombeiro A J L 2007 3D hydrogen bonded heteronuclear $\mathrm{Co}^{\mathrm{II}}, \mathrm{Ni}^{\mathrm{II}}, \mathrm{Cu}^{\mathrm{II}}$ and $\mathrm{Zn}^{\mathrm{II}}$ aqua complexes derived from dipicolinic acid Inorg. Chim. Acta 360506

125. Gao H, Yi L, Zhao B, Zhao X, Cheng P, Liao D and Yan S 2006 Synthesis and characterization of metalorganic frameworks based on 4-hydroxypyridine-2,6dicarboxylic acid and pyridine-2,6-dicarboxylic acid ligands Inorg. Chem. $\mathbf{4 5} 5980$

126. Aghabozorg H, Manteghi F and Sheshmani S 2008 A brief review on structural concepts of novel supramolecular proton transfer compounds and their metal complexes J. Iran. Chem. Soc. 5184

127. Mirzaei M, Aghabozorg H and Hosseini E H 2011 A brief review of structural concepts of novel supramolecular proton transfer compounds and their metal complexes part II J. Iran Chem. Soc. 8580

128. Das B and Baruah J B 2010 Cooperativity on selective products in one pot reactions of 2,6pyridinedicarboxylic acid and ethylenediamine with metal ions Inorg. Chem. Commun. 13350

129. Shankar K and Baruah J B 2016 Modulation of fluorescence emissions of copper(II) 2,2-biquinoline-4,4dicarboxylate ChemistrySelect. 13038

130. Das B and Baruah J B 2013 Water clusters in mixed ionic complexes with metal dipicolinate anions $\mathrm{J}$. Mol. Struct. 1034144

131. Das B and Baruah J B 2010 Coordinated cations in dipicolinato complexes of divalent metal ions Inorg. Chim. Acta 3631479

132. Ma C, Chen C, Chen F, Xhang X, Zhu H, Liu Q, Liao D and Li L 2003 Syntheses and structures of three types of hybrid metal dipicolinato complexes induced by alkali metal ion and the semiconductor character Bull. Chem. Soc. Jpn. 76301

133. Ikeda T, Takayama M, Kumar J, Kawai T and Haino T 2015 Novel helical assembly of a Pt(II) phenylbipyridine complex directed by metal-metal interaction and aggregation-induced circularly polarized emission $\mathrm{Dal}$ ton Trans. 4413156

134. MacDonald J C, Dorrestein P C, Pilley M M, Foote M M, Lundburg J L, Henning R W, Schultz A J and Manson J L 2000 Design of layered crystalline materials using coordination chemistry and hydrogen bonds J. Am. Chem. Soc. 12211692
135. Meeuwissen J and Reek J N H 2002 Supramolecular catalysis beyond enzyme mimics Nat. Chem. 2615

136. Diab L, Smejkal T, Geier J and Breit B 2009 Supramolecular catalyst for aldehyde hydrogenation and tandem hydroformylation-hydrogenation Angew. Chem. Int. Edit. 488022

137. Park J, Lang K, Abboud K A and Hong S 2008 Selfassembled dinuclear cobalt(II)-salen catalyst through hydrogen-bonding and its application to enantioselective nitro-aldol Henry reaction J. Am. Chem. Soc. 130 16484

138. Martín C, Whiteoak C J, Martin E, Escudero-Adan E C, Galan-Mascaros J R and Kleij A W 2014 Synthesis and structural features of $\mathrm{Co}$ (II) and $\mathrm{Co}$ (III) complexes supported by aminotrisphenolate ligand scaffolds Inorg. Chem. 5311675

139. Mote N R, Patel K, Shinde D R, Gaikwad S R, Koshti V S, Gonnade R G and Chikkali S H 2017 H-Bonding assisted self-assembly of anionic and neutral ligand on metal: A comprehensive strategy to mimic ditopic ligands in olefin polymerization Inorg. Chem. 5612448

140. Noveron J C, Lah M S, Sesto R E D, Arif A M, Miller J S and Stang P J 2002 Engineering the structure and magnetic properties of crystalline solids via the metaldirected self-assembly of a versatile molecular building unit J. Am. Chem. Soc. 1246613

141. Nakajima K and Hori A 2014 Dynamic transformation and reversible guest encapsulations of pseudopolymorphs of a fully fluorinated $\beta$-diketonate Pd(II) complex Cryst. Growth Des. 143169

142. Bouzaid J, Schultz M, Lao Z, Bostrom T and McMurtrie J 2015 Supramolecular selection in molecular alloys Cryst. Growth Des. 1562

143. Huang $\mathrm{T} J$, Thiang $\mathrm{Z} X$, Yin $\mathrm{X}$, Tang $\mathrm{C}$, Qi $\mathrm{G}$ and Gong $\mathrm{H} 2016\left(\mathrm{CH}_{3} \mathrm{NH}_{3}\right)_{2} \mathrm{PdCl}_{4}$ : A compound with two-dimensional organic-inorganic layered perovskite structure Chem. Eur. J. 222146

144. Dohner E E R, Hoke E T and Karunadasa H I 2014 Self-assembly of broadband white-light emitters J. Am. Chem. Soc. 1361718

145. Ritchie C, Burkholder E M, Long D-L, Adam D, Kogerler P, Cronin L 2007 Exploiting the multifunctionality of organocations in the assembly of hybrid polyoxometalate clusters and networks Chem. Commun. 5468

146. Mao L, Tsai H, Nie W, Ma L, Im J, Stoumpos C C, Malliakas C D, Hao F, Wasielewski M R, Mohite A D and Kanatzidis M G 2016 Ruddlesden-popper hybrid lead Iodide perovskite 2D homologous semiconductors Chem. Mater. 287781

147. Li Y Y, Lin C K, Zheng G L, Cheng Z Y, You H, Wang W D and Lin J 2006 Novel [110]-oriented organicinorganic perovskite compound stabilized by N-3aminopropyl.imidazole with improved optical properties Chem. Mater. 183463

148. Guloy A M, Tang Z, Miranda P B and Srdanov V I 2001 A new luminescent organic-inorganic hybrid compound with large optical nonlinearity $A d v$. Mater. 13833

149. Hogan G A, Rath N P and Beatty A M 2011 A stable hydrogen-bonded coordination network with removable guests Cryst. Growth Des. 113740 
150. Shankar K and Baruah J B 2016 Mixed anionic and inclusion complexes of nickel(II) with nitroaromatics showing selectivity in oxygen- $\pi$ interactions Inorg. Chim. Acta 453135

151. Shankar K and Baruah J B 2016 Tetranuclear cobalt complexes as nano-dimensional template for inclusion of nitrophenols ChemistrySelect. 15152

152. Yagishita S, Himegi A, Kanazashi K, Ohishi T, Ishikawa R, Hamaguchi T and Kawata S 2017 Structural transformations of layered structures constructed from $\mathrm{Cu}(\mathrm{II})-$ chloranilate monomer compounds Dalton Trans. 462966

153. Ferlay S, Dechambenoit P, Kyritsakas $\mathrm{N}$ and Hosseini M W 2013 Molecular tectonics: Tuning the dimensionality and topology of extended cyanocuprate networks using a bisamidinium cation Dalton Trans. 42 11661

154. Braga D, d'Agostino S, D'Amen E, Grepioni F, Genovese D, Prodi L and Sgarzi M 2013 A quest for supramolecular gelators: SilverI. complexes with quinoline-urea derivatives Dalton Trans. 4216949

155. Boyd P D W and Reed C A 2005 Fullerene-porphyrin constructs Acc. Chem. Res. 38235

156. Wang B, Zheng S, Saha A, Bao L, Lu X and Guldi DM 2017 Preparation and optical properties of fullerene/ferrocene hybrid hexagonal nanosheets and large-scale production of fullerene hexagonal nanosheets J. Am. Chem. Soc. 13910578 